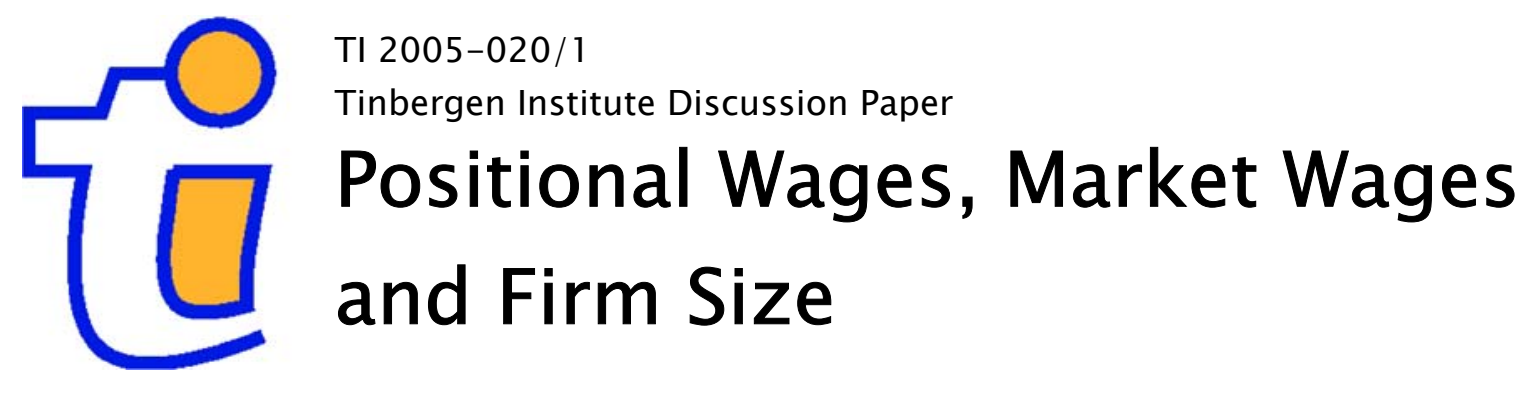

René van den Brink ${ }^{1}$

Pieter H.M. Ruys ${ }^{2}$

1 Department of Econometrics, Faculty of Economics and Business Administration, Vrije Universiteit Amsterdam, and Tinbergen Institute,

2 Department of Econometrics and OR, CentER and TILEC, Tilburg University. 


\section{Tinbergen Institute}

The Tinbergen Institute is the institute for economic research of the Erasmus Universiteit Rotterdam, Universiteit van Amsterdam, and Vrije Universiteit Amsterdam.

Tinbergen Institute Amsterdam

Roetersstraat 31

1018 WB Amsterdam

The Netherlands

Tel.: $\quad+31(0) 205513500$

Fax: $\quad+31(0) 205513555$

Tinbergen Institute Rotterdam

Burg. Oudlaan 50

3062 PA Rotterdam

The Netherlands

Tel.: $\quad+31(0) 104088900$

Fax: $\quad+31(0) 104089031$

Please send questions and/or remarks of nonscientific nature to driessen@tinbergen.nl.

Most TI discussion papers can be downloaded at http://www.tinbergen.nl. 


\title{
Positional Wages, Market Wages and Firm Size*
}

\author{
René van den Brink ${ }^{\dagger}$ and Pieter H.M. Ruys ${ }^{\ddagger}$
}

February 2005

\begin{abstract}
We model a firm in an institutional market setting, consisting of a production technology and its governance. The governance consists of a hierarchical firm structure, a cost efficiency parameter, and an internal pay system. The depth of the firm is determined by profit maximization under the participation restriction that lowest wages meet reservation wages. Reservation wages are endogenously determined in the institutional market economy. We give conditions guaranteeing a finite optimal firm size. Using CES-production technologies we illustrate how firm size depends on labor substitutability, and show that a linear technology yields the deepest structure and a complementary the flattest structure.
\end{abstract}

JEL-classification: D23, J24, L22.

Keywords: Optimal firm size, governance, hierarchy, internal organization structure, cooperative game, permission value, labor substitutability, general equilibrium.

\footnotetext{
${ }^{1}$ We thank Eric van Damme, Rob Gilles and Dolf Talman for their comments on a previous version of this paper.

${ }^{2}$ Department of Econometrics and Tinbergen Institute, Free University, De Boelelaan 1105, 1081 HV Amsterdam, The Netherlands, E-mail: jrbrink@feweb.vu.nl.

${ }^{3}$ Department of Econometrics and OR, CentER and TILEC, Tilburg University, P.O. Box 90153, 5000 LE Tilburg, The Netherlands, E-mail: P.H.M.Ruys@uvt.nl .
} 


\section{Introduction}

This paper addresses the entrepreneurial problem of determining endogenously the optimal size of a firm in a competitive market environment, when the production possibilities interact with the labor organization and the governance of the firm. It has been observed by Rajan and Zingales (2001) that at the root of most enterprizes generating economic surplus is an entrepreneur with a unique critical resource such as an idea, good customer relationships, a new tool, or superior management technique. We represent that unique resource by two concepts: a production outcome function specifying the various production possibilities from which to select one, and the firm's governance, specifying the management of transactions and agency relations in the firm when realizing the chosen production technology. The firm's governance (or rather the entrepreneur's governance) specifies roles or positions within the firm and the agency relations connecting these roles and positions. The governance is adapted to the technology and to the size of the firm. The interaction between these two concepts, the technology and the governance, determines the productivity of positions and of coalitions of positions for workers.

We follow the seminal paper of Alchian and Demsetz (1972) who state that production is in principle a collective effort, see also Hart and Moore (1990) and Ichiishi (1993). Therefore we use a cooperative game theoretic model in which coalitions or teams of workers can generate a production outcome when they are coordinated by their managers. The technology is a set of production outcome functions, each adapted to the products or services supplied, and to the amounts supplied, but invariant for the characteristic degree of complementarity or substitution between the various positions within the firm. A choice of production affects the organization and the governance of the firm.

The firm's governance is described by three elements. First, a network of principal-agent relations between well defined labor positions in the firm is defined. The top-position in the firm, that is the one having no principal and is occupied by the CEO, chooses the size of the organization and the governance that maximizes the profit of the firm. The front-positions in the firm, which have no agent within the firm, generate the added value of the firm by producing services and selling these on a product market. These front-positions enter the 
firm's production function as inputs.

Second, the network of principal-agent relations is supposed to be a hierarchy in which each agent at some level (except the lowest level) is a principal for agents at a consecutive level. Such a principal is called a manager or coordinator who translates, monitors, and adapts the various tasks and responsabilities of its subordinates in order to let them comply with the overall mission of the firm. We assume this mission to be given by the top principal, who is aiming at profit maximization ${ }^{1}$. Increasing the number of levels broadens the productive base of the organization but also increases the level-dependent agency costs. These costs are increasing in the number of hierarchical levels. Examples of such costs are the translation of the central strategic mission to each operational level, or the agency costs involved in the processing and control of level-dependent budgets and information, implying a loss of control of a coordinator over the behavior of its direct subordinates, see, e.g. Williamson (1967). These agency costs are expressed by a discount factor between 0 and 1, which indicates the percentage loss of output for each level involved.

In order to distribute the value added by the firm among the various positions in the firm, we introduce a distribution function which is characterized by principles used in labor negotiations. Finally, a pay system is determined by a distribution function which distributes the value added of the firm between the profit for the owner position and the different wages for the employee positions in the firm. Since the wages and profit are assigned to the positions in the firm, and not directly to the emloyees who occupy these positions, we refer to these as positional wages and positional profit.

By choosing a quantity to be supplied, the CEO chooses a feasible production technology and the corresponding organization and governance. Labor is searched for and employed in the various positions in the organization with wages at least equal to the given market reservation wage. Given the prices on the product markets, the value added of the firm is determined. Positional wages and the firm's profit are then derived from the distribution function. The CEO will choose that quantity that maximizes its profit. Since these positional

\footnotetext{
${ }^{1}$ We do not specify how this mission is reformulated to subgoals down in the firm organization and how, in the upward direction, information about production and sales is communicated and translated in operational terms for higher levels in the firm organization, see Radner (1992) for a survey about the information processing and decentralized decision making in hierarchical firms.
} 
wages are based on cooperative behavior as determined by the governance of the firm, they may deviate from market wages, similar as is the case in efficiency wage theory, see e.g., Stiglitz (1976), Akerlof (1984) and Yellen (1984).

The effectiveness of the firms' coordination is determined by three parameters: the span of control of the firm ${ }^{2}$, the above mentioned discount factor which can be interpreted as an agency efficiency parameter, and the number of levels in the internal organization. The values of the first two parameters are interdependent and are given a priori, together with the choice of technology. Given these parameters and the workers' capacity, the owner has to decide upon the number of coordination levels. This model of a homogeneous firm is in line with a.o., Williamson (1967), Coleman (1980), and Radner (1992). Such an organization structure has been called a regular hierarchy by Beckman (1988). In these papers attention is focussed on the labor input, both in production and in internal organization. Other factors of production are assumed to have a constant cost per unit of production.

The first novelty of this paper is the introduction of an internal cooperative pay system in a firm. We study its effect on the optimal size of the firm. Determining the pay system by a cooperative solution implies that all positions earn a share in the value added that can be generated by different compositions of actively occupied positions in the firm. Therefore we have refered to the wages that are assigned to the different positions as positional wages ${ }^{3}$. This cooperative solution has to satisfy three axioms, which are reasonable conditions used in collective wage agreements.

The second novelty is the impact of the shape of the production function on the governance. The owner of the firm chooses the size of the firm that maximizes its profit, given the productivity of the employees (workers and intermediate coordinators) as determined by the production technology and adapts the internal organization structure conformingly. Next he offers the wages for the various positions in the firm according to the pay system. These

\footnotetext{
${ }^{2}$ Since the workers have to be coordinated, their number is not arbitrary and depends on the size of the internal organization structure. The simplifying assumption that the span of control is equal for each coordinator can only be made if the workers are homogeneous and, for each level in the firm, the coordinators are identical. Between levels their capacities and tasks will differ. In such a firm the number of levels completely determines the structure of the firm.

${ }^{3}$ In, e.g., Williamson (1967) and Keren and Levhari (1979, 1983), models are discussed that take the wage of the productive workers in the firm to be fixed and independent of the structure of the firm and the production function.
} 
positional wages are equal within each level in the homogeneous organization. We assume the labor market to be compartmentalized into homogeneous levels. If an employee accepts an offer, he is admitted to a position in the organization and voluntarily subjects himself to the hierarchy of the firm, see, e.g., Coleman (1980), Rosen (1982), and Simon (1991). If the positional wage that is offered to the workers falls below their external reservation wage given by the labor market, then they will not accept a position in the firm and those positions in the firm cannot be activated. If profit falls below the external reservation profit as determined by the capital market then the owner will not activate the firm. The firm structure is thus determined by maximizing profit under these two participation constraints which are determined by the external environment of the firm. In principle, the profit maximizing owner may be willing to pay an employee more than the reservation wage if his or her internal productivity allows to do so.

The third novelty is the introduction of an institutional market economy which consists of a representative firm as described above, a finite set of consumers and a finite set of competitive markets. The firm demands labor and supplies the consumption good, while the consumers demand the consumption good and supply labor. The output price and reservation wage mentioned above are replaced by the corresponding market prices ${ }^{4}$. Given wages and output prices we determine the optimal size of the firm as described above, but with the exogenously given output price and the reservation wage replaced by the market output price and market wage, respectively. This yields market supply of the consumption good and market demand for labor. Assuming consumer preferences to satisfy the standard regularity conditions, aggregation of individual demand and supply yields market demand for the consumption good and market supply of labor. We define an institutional market equilibrium consisting of an output price, a wage and a firm size such that (i) firm size is optimal given the prices, and (ii) the prices are competitive equilibrium prices at which market supply equals market demand given the firm size. In other words, in an institutional market equilibrium the external competitive equilibrium prices are consistent with the firms' internal equilibrium (i.e. profit maximizing size). We show that in general there may arise discontinuities in the

\footnotetext{
${ }^{4}$ To better understand the equilibrium notion introduced in this section we ignore reservation profit.
} 
firms supply and demand functions resulting from the fact that profit might be decreasing in firm size for certain firm sizes. As a consequence, also the institutional market equilibrium need not exist. However, such an equilibrium exists if the optimal firm size is continuous in prices, which is the case in, for example, linear and complementary production technologies.

The paper is organized as follows. In Section 2, the model is introduced. In Section 3 we provide conditions under which an optimal firm size exists, i.e. when it is finite. The effect of substitutability of labor inputs on the optimal size of the firm is studies in Section 4 using constant elasticity of substitution (CES) production technologies. We show that in case working labor is substitutable, for reasonable values of the effectiveness parameters, the owner will choose the deepest organization restricted by the reservation wage of workers. An opposite result is derived for Cobb-Douglas production technologies with indispensable labor, in which case the flattest organization is chosen. In Section 5 we discuss the feature that the optimal firm size might depend discontinuously on the market prices. In a general equilibrium framework this may lead to non-existence of equilibria. Finally, in Section 6 we describe related literature and in Section 7 we make some concluding remarks.

\section{The model}

In this section the technological possibilities and the organizational governance of the firm are formally described.

\subsection{The technology: outcome possibilities and its transaction value}

The firm's technology is described by a set of outcome functions, which depend not only on the workers as labor inputs, but also on the size and structure of roles or positions to which workers get access. These workers will occupy the so-called front-positions in the firm. The firm's outcome is the result of interaction between these workers in the front-positions of the firm, the service performers, and their clients, the service receivers ${ }^{5}$. This outcome defines

\footnotetext{
${ }^{5}$ We restrict the firm's output and its environment to marketable products and services, which allows for identifying the entrepreneur with an owner of the firm, and for embedding the firm in a general equilibrium context.
} 
the quality of the service rendered per unit service, on a cardinal quality index scale. The quantity is determined by the number of front-positions. Suppose firstly that the set $W$ of front workers is given, and denote $2^{W}$ as the set of subsets or coalitions of front-positions. Then the firm's outcome is defined by the outcome function $f: 2^{W} \rightarrow \mathbb{R}$. This outcome has to be sold to buyers by means of monetary transactions on a market, resulting in a transaction value.

We assume the set of front-positions to be homogeneous, meaning that all front-positions are identical in the production process. This means that also the outcome function is homogeneous, i.e. it can be written as a function $f:\{1, \ldots,|W|\} \rightarrow \mathbb{R}$ defined on the number of (identical) front-positions. Further, we assume the outcome function to be monotone implying that $f(k) \leq f(l)$ if $k \leq l$. An important subclass of monotone outcome functions is the class of supermodular outcome functions (see. e.g. Milgrom and Roberts (1994)) which exhibit increasing scale returns in the sense that they favor producing with larger sets of front-positions. Moreover, we assume that nothing is produced if no worker is providing any labor input, i.e., $f(0)=0$.

The owner of the firm gives the managers access to the production technology and allows the front-workers to represent the firm to the clients, i.e. taking the front-position. Similarly he gives the middle management access to the internal organization by allowing them to occupy the management positions in order to enhance the productivity of the front-workers. The outcome provided by the firm is sold at a competitive output price $p>0$. Thus, if all front positions are effectively occupied, then the transaction value is the firm's outcome multiplied by the (market) price and is equal to $p f(|W|)$.

Next, we parameterize the size and structure of roles or positions in a firm by the variable $n$, the meaning of which is to be specified in the next subsection. So the set of front-positions will be denoted by $W_{n}$ and the set of outcome functions at the disposal of the entrepreneur is defined by $\left\{f_{n} \mid n=1, \ldots, \bar{n}\right\}$, with $\bar{n}$ sufficiently large. The transaction value is accordingly written as $p f_{n}\left(\left|W_{n}\right|\right)$. 


\subsection{The internal governance of the firm's organization}

A service cannot be rendered unless it is managed. The main tool of management for the entrepreneur is the internal governance structure of the firm. It may be seen as the institutional hull that realizes and supports, but also constraints the technology, represented here by the set of outcome functions. The governance of a firm determines tasks, competencies, and incentives for the various roles in a firm such that the expected performance of the middle management optimally supports the productivity of the workers in the front-positions, in order to maximize the firm's value-added.

Ideally, the entrepreneur should adapt the governance to the technology of the firm which may require strong or weak interaction between workers. The raison d'etre of the firm implies that all roles or activities of the firm show some degree of interaction, which is based upon the technology of the firm. An army requires strong interaction, whereas a modern car factory allows for outsourcing many activities. But the ideal correspondence between technology and governance is disturbed by several factors, such as uncertainty regarding technological change, familiarity of workers with established governance systems, and the transaction costs involved with a change of organization. Furthermore, the choice of governance also depends on the economic environment of the firm. An unstable or a less organized external environment will favor vertical integration in order to internalize productive spillovers between partial activities of the firm.

In this paper we simplify the problem by considering a standard hierarchical type of governance, which can be extended or contracted by varying the number of levels. That allows us to consider the level of the governance as specification of the parameter $n$ for the size of the output or the supply of the firm, which output is given by the outcome function of the front-workers ${ }^{6}$.

For any given value of $n$, the firm's governance is described by a hierarchical network $\left(N_{n}, S_{n}\right)$ of principal-agent relations, in which the set of nodes, $N_{n}$, represents a set of well

\footnotetext{
${ }^{6}$ The valuation of output can also be modelled as resulting from market forces. In both cases, the valuation is determined by agents who are competent to enter into monetary transactions, and therefore called the transaction value. One also may choose to focus on the quality of the product, the personal value, which is determined by the interaction between service-performers, that is, the front-workers, and service-receivers, that is, the clients or patients.
} 
defined roles ${ }^{7}$ or labor position in the firm, and the directed graph $S_{n} \subset N_{n} \times N_{n}$ represents the set of principal-agent relations, in short, agency relations $(i, j)$ with principal $i$ and agent $j$ in $N_{n}$. It is assumed that there is a unique position having no principal, which is called the top position, $i_{0}$, and which will be occupied by the owner of the firm. It also is assumed that each agent has one principal, so there is no cycle in the graph. It follows that the internal organization structure $\left(N_{n}, S_{n}\right)$ has a tree structure, its root being the top-position $i_{0}$, and the end-points forming a nonempty set of positions having no agents. This set corresponds with the set of front-positions in the firm: $W_{n}=\left\{i \in N_{n} \mid S_{n}(i)=\emptyset\right\}$. The labor input of the production process is provided by the workers occupying the front-positions. Obviously, a firm with structure $\left(N_{n}, S_{n}\right)$ can produce according to a production outcome function $f_{n}$ if and only if the set of front-positions in the structure $W_{n}$ corresponds to the domain of the outcome function. The other positions, $N_{n} \backslash\left(W_{n} \cup\left\{i_{0}\right\}\right)$, are the intermediate coordinator positions which serve to increase the productivity of the front-positions. Since the internal organization structure has a hierarchical tree structure, different levels can be distinguished in the internal organization, where each position in a given level has the same distance to the top-position.

Let $N_{0}=\left\{i_{0}\right\}$ represent the top-level with the owner-position of the firm. Then, recursively we define the sets $N_{\ell}=N_{\ell-1} \cup\left\{i \in N_{n} \backslash N_{\ell-1} \mid i \in S_{n}(j)\right.$ for some $\left.j \in N_{\ell-1}\right\}$, for $\ell=1, \ldots, n$. So, the sets $L_{\ell}=N_{\ell} \backslash N_{\ell-1}, \ell=1, \ldots, n$, form the different hierarchical levels in the firm. Additional structure is required to guarantee that the lowest level $N_{n} \backslash N_{n-1}$ is equal to the set of positions having no agent. This is obtained by assuming that each principal in the firm has the same number of agents ${ }^{8}$. This number is called the span of control and is denoted by $s$. So $\left|S_{n}(i)\right|=s$ for all $i \in M_{n}=N_{n} \backslash W_{n}$. Given the top-level $L_{0}=N_{0}$, the positions at some level, $\ell$, of the firm are represented by $L_{\ell}=\left\{i_{\ell, 1}, \ldots, i_{\ell, s^{\ell}}\right\}$, for $\ell=1, \ldots, n$. Denoting the top-position $i_{0}$ alternatively by $i_{0,1}$ as the first position in level 0 , the corresponding relational structure is $S_{n}\left(i_{l, k}\right)=\left\{i_{l+1,(k-1) s+1}, \ldots, i_{l+1, k s}\right\}, l=0, \ldots, n-1$ and $k=1, \ldots, s^{l}$. In Figure 1 the internal organization structure of a one-level and two-level

\footnotetext{
${ }^{7}$ The model is therefore a role assignment model as introduced by Everett and Borgatti (1991), see also Pekec and Roberts (2001).

${ }^{8}$ We can allow for firms with a non-uniform span of control and front-positions in different levels. However for notational convenience we do not allow for such firms in this paper.
} 
firm is illustrated for the case that the span of control, $s$, equals 2 .

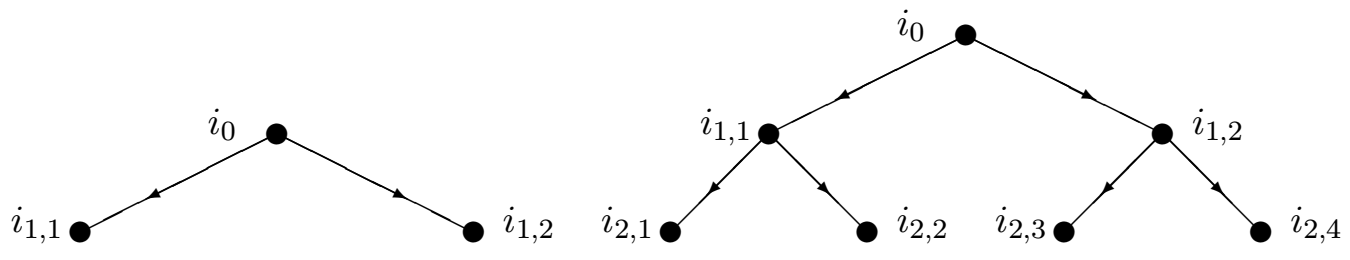

Figure 1: A one-level and a two-level internal organization structure with span of control 2

In an $n$-level firm the number of positions equals $\left|N_{n}\right|=\sum_{\ell=0}^{n} s^{\ell}=\left(s^{n+1}-1\right) /(s-1)$, the number of principal positions equals $\left|M_{n}\right|=\sum_{\ell=0}^{n-1} s^{\ell}=\left(s^{n}-1\right) /(s-1)$, and the number of front-positions is equal to $\left|W_{n}\right|=s^{n}$. The coordination intensity ${ }^{9}$ equals the ratio $\left|M_{n}\right| /\left|W_{n}\right|$ and is approximately equal to $1 /(s-1)$, if $n$ is large enough.

\subsection{Efficiency costs and benefits: the level-dependent generation of value added}

The sequence of agency relations decentralizes decision making at each consecutive level and allows to decrease the complexity of the decision problem at each level. It results, however, in certain level-dependent agency costs. These agency costs per level are stated as a percentage of final production and are represented by $(1-\alpha)$, with the parameter $\alpha$ strictly between zero and one. Agency costs are therefore increasing in the number of hierarchical levels. Adding a level in the internal organization may thus benefit the owner by increasing the scale of production, at the cost of an increase in agency costs.

The positions for the production factor labor are distinguished in front-positions and coordinator positions. The owner of the firm gives the workers access to the production technology by allowing the workers to occupy the front-positions. Similarly he gives the coordinators access to the internal organization by allowing them to occupy the coordinator positions. As we have seen, if all front-positions are effectively occupied then a transaction

\footnotetext{
${ }^{9}$ This concept is introduced by Gordon (1994) in order to estimate and explain differences in the span of control over various countries.
} 
value equal to $p f_{n}\left(\left|W_{n}\right|\right)=p f_{n}\left(s^{n}\right)$ is generated. Net revenue or value added is obtained by subtracting the level-dependent cost from this gross revenue ${ }^{10}$ yielding $p \alpha^{n} f_{n}\left(s^{n}\right)$. Note that the parameter $\alpha$, being the complement of the level-dependent agency cost parameter, can be seen as an agency efficiency parameter. It may correlate with the span of control parameter $s$, but both are given here.

\subsection{The level-dependent distribution of value added: positional wages and profit}

By definition the value added of a firm also equals the reward paid to the production factors, i.e., the value added equals the sum of the internal wages and the profit. The value added of a firm is distributed among all positions in the firm according to some pay system being a function $\varphi$ which assigns a distribution of value added to every outcome function $f_{n}$ with internal organization structure $\left(N_{n}, S_{n}\right)$ and level-dependent agency efficiency parameter $\alpha$. Since the internal organization structure and level dependent agency efficiency are determined by $n$, we denote the reward assigned to position $i \in N_{n}$ in a firm producing according to $f_{n}$ by $\varphi_{i}\left(f_{n}\right)$. This pay system determines the internal wages that eventually are paid to the laborers occupying the positions. Since the rewards are assigned to and depend on the positions in the firm structure we refer to these wages as positional wages. We assume this pay system to satisfy the following three properties. First, it guarantees a balanced budget ${ }^{11}$, i.e., $\sum_{i \in N_{n}} \varphi_{i}\left(f_{n}\right)=p \alpha^{n} f_{n}\left(s^{n}\right)$ for every firm size $n$ and outcome function $f_{n}$. Secondly, it satisfies vertical monotonicity meaning that a supervisor does not receive a lower wage than its successors, i.e., for every firm size $n$ and every monotone outcome function $f_{n}, \varphi_{i}\left(f_{n}\right) \geq \varphi_{j}\left(f_{n}\right)$ for all $i \in M_{n}$ and $j \in S_{n}(i)$. Finally, we assume it to be symmetric meaning that in a homogeneous firm it assigns the same positional wage to all positions within the same coordination or worker level. Since we assume a homogeneous firm with a symmetric pay system we can speak about wages assigned to levels instead of wages assigned to positions, i.e., $\varphi_{k}\left(f_{n}\right)=\varphi_{i}\left(f_{n}\right)$ for all $i \in N_{k}, k \in\{1, \ldots, n\}$. Similarly, the profit of the

\footnotetext{
${ }^{10}$ For notational convenience we do not consider material cost that depend on the level of production. Considering these costs to have given input price $c>0$ does not change the results.

${ }^{11} \mathrm{In}$ game theory this property is called efficiency.
} 
owner position is denoted by $\varphi_{0}\left(f_{n}\right)$. The endogenously determined positional wages are an important difference between our model and the models of, for example, Williamson (1967) and Keren and Levhari $(1979,1983)$ where the wages of the workers are independent of the firm structure.

Definition 2.1 An n-level firm is a tuple $F_{n}=\left(f_{n},\left(N_{n}, S_{n}\right), \alpha, \varphi\right)$ with: (i) a monotone outcome function $f_{n}$ that is defined on a set of front-positions $W_{n}$, (ii)an internal organization structure $\left(N_{n}, S_{n}\right)$ having a tree structure with constant span of control on the non-empty and finite set of positions $N_{n}$ such that $W_{n}=\left\{i \in N_{n} \mid S_{n}(i)=\emptyset\right\}$, iii) an agency efficiency parameter $0<\alpha<1$, and (iv) a pay system $\varphi$ that yields a distribution of value added in positional wages and profit satisfying budget neutrality, vertical monotonicity and symmetry.

The set of all $n$-level firms is denoted by $\mathcal{F}_{n}$. In order to endogenously determine the optimal firm size we need to define a firm with variable number of levels, i.e. we need to describe how the firm looks like for every possible size ${ }^{12}$.

Definition 2.2 $A$ firm is a set $F=\left\{F_{n}\right\}_{n \in \mathbb{N}}$ of n-level firms $F_{n} \in \mathcal{F}_{n}$ rendering the same service.

\section{The optimal size of the firm}

Since the profit of a firm depends on firm size, the owner-employer can determine profit by choosing the size of the firm. Since the span of control of the firm is assumed to be given, the only way to increase the number of front-positions is to increase the number of levels in the firm. An extra level allows more workers to be active. It has a positive effect on value added through the monotone outcome function. On the other hand, there is the negative effect of the level dependent agency cost. The owner of the firm chooses $n$ in order to maximize profit.

Suppose that the owner can choose a firm size between 1 and $\bar{n}$ without any constraints. In that case the maximal profit equals $\bar{\varphi}_{0}(\bar{n})=\max \left\{\varphi_{0}\left(f_{n}\right) \mid n \in\{1, \ldots, \bar{n}\}\right\}$ with $\bar{\varphi}_{0}(0)=0$. Thus, by $\bar{\varphi}_{0}$ we have written profit as a non-decreasing function of maximal possible firm size

\footnotetext{
${ }^{12}$ The firm has been defined on the set of levels which characterize the organization structure of the firm. In principle any parameter of the firm may be chosen.
} 
$\bar{n}$. We call $\bar{\varphi}_{0}$ the level-dependent profit function, see Figure 2. (In the figures we assume for simplicity that the level $n$ can be any non-negative real number, i.e., $n \in \mathbb{R}_{+}$.)
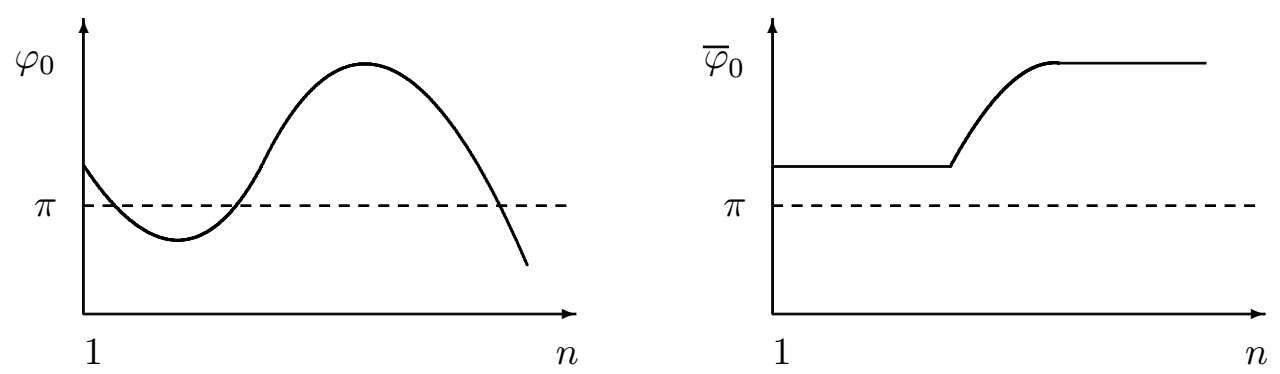

Figure 2: Profit $\varphi_{0}$ and level dependent-profit $\bar{\varphi}_{0}$ for owners as function of firm size

Besides the unit output price $p>0$, the external organization of the firm is represented by a reservation wage $w>0$ for workers, and a reservation profit $\pi>0$ for the owner. In order for the firm to be active the front- and coordinator positions have to be occupied by employees (i.e. workers and managers). The potential employees of a firm will accept a position in a firm with $n$ levels if and only if the positional wages offered do not fall below their reservation wage $w$. Therefore, in equilibrium the owner chooses firm size $n$ such that profit is maximal under the constraint that the positional wages offered to the workers ${ }^{13}$ exceed their reservation wage $w$. If profits at this optimal size of the internal organization are lower than the reservation profit $\pi$, then the owner will not activate the firm. So, the only firm sizes that are supported by the external environment of the firm are the ones in the set $N(w, \pi, p)=N^{o}(w, p) \cap N_{o}(\pi, p)$, where $N^{o}(w, p)=\left\{n \in \mathbb{N} \mid \varphi_{n}\left(f_{n}\right) \geq w\right\}$ is the set of levels that satisfies the worker participation constraint, and $N_{o}(\pi, p)=\left\{n \in \mathbb{N} \mid \varphi_{0}\left(f_{n}\right) \geq \pi\right\}$ is the set of levels that satisfies the owner perticipation constraint. In general, the set $N(w, \pi, p)$ can be empty, disconnected or unbounded.

The optimal coordination level $n^{*}$ is the lowest level of coordination that maximizes profit under the constraints that wages exceed the reservation wage and profit exceeds the reservation profit.

\footnotetext{
${ }^{13}$ We assume implicitly that the labor market is sufficiently differentiated to provide for each hierarchical level a competitive partial labor market. Any level may be chosen as a benchmark. We have chosen the lowest level. This assumption allows us to compare only the lowest wage offered by the firm with the reservation wage of the corresponding compartment on the labor market since vertical monotonicity of the permission value implies that the wage offered to a coordinator is always greater or equal to the wages offered to its subordinate workers. Thus, if the workers accept the wages offered then also the coordinators accept the wages offered to them.
} 
Definition 3.1 The optimal coordination level of a firm $F$ given reservation wage $w$, reservation profit $\pi$ and price $p$ is the level given by

$$
n^{*}(w, \pi, p)=\min \left\{n \in N(w, \pi, p) \mid \varphi_{0}\left(f_{n}\right)=\max _{\hat{n} \in N(w, \pi, p)} \varphi_{0}\left(f_{\hat{n}}\right)\right\}
$$

if there exists $n \in N(w, \pi, p)$ with $\varphi_{0}\left(f_{n}\right) \geq 0$, and $n^{*}(w, \pi, p)=0$ otherwise.

The following proposition shows that the set $N(w, \pi, p)$ is bounded if there is a level $\tilde{n}$ such that average productivity of the labor inputs is non-increasing in firm size $n \geq \tilde{n}$, i.e. $f_{n+1}\left(s^{n+1}\right) \leq s f_{n}\left(s^{n}\right)$ for all $n \geq \tilde{n}$. We discuss some examples of such production functions in the next section.

Proposition 3.2 Let $F$ be a firm for which there exists a $\tilde{n} \in \mathbb{N}$ such that average labor productivity is non-increasing in firm size $n \geq \tilde{n}$. Further, let a positive output price $p$, reservation-wage $w$ and reservation profit $\pi$ be given exogenously. Then the set $N(w, \pi, p)$ of firm levels that are supported by the external environment of the firm is bounded.

\section{ProOF}

First, suppose that average labor productivity is non-increasing in firm size $n \geq 0$. Then there exists a constant $c \in \mathbb{R}_{+}$such that $f_{n}\left(s^{n}\right) \leq c s^{n}$, and thus total value added of a firm with size $n$ satisfies $p \alpha^{n} f_{n}\left(s^{n}\right) \leq p c(\alpha s)^{n}$. Since the number of positions in an $n$ level firm equals $\left|N_{n}\right|=\frac{s^{n+1}-1}{s-1}$, efficiency, vertical monotonicity and symmetry of the pay system $\varphi$ imply that $\varphi_{n}\left(f_{n}\right) \leq \frac{p \alpha^{n} f_{n}\left(s^{n}\right)}{\left|N_{n}\right|} \leq \frac{p c(\alpha s)^{n}(s-1)}{s^{n+1}-1}=\frac{p c \alpha^{n}\left(s^{n+1}-s^{n}\right)}{s^{n+1}-1} \leq p c \alpha^{n}$. So, for $\alpha<1$ it holds that $\lim _{n \rightarrow \infty} \varphi_{n}\left(f_{n}\right)=0$. But then $\left\{n \in \mathbb{N} \mid \varphi_{n}\left(f_{n}\right) \geq w\right\}$ is bounded for $w>0$, and so is $N(w, \pi, p) \subset\left\{n \in \mathbb{N} \mid \varphi_{n}\left(f_{n}\right) \geq w\right\}$.

Next, suppose that there exists a $\tilde{n} \in \mathbb{N}$ such that average labor productivity is nonincreasing in firm size $n \geq \tilde{n}$. Then there exists a constant $c \in \mathbb{R}_{+}$such that for $n \geq \tilde{n}$, it holds that $f_{n}\left(s^{n}\right)-f_{\tilde{n}}\left(s^{\tilde{n}}\right) \leq c s^{n-\tilde{n}}$, and thus for $\alpha<1$ we have $p \alpha^{n} f_{n}\left(s^{n}\right)-p \alpha^{\tilde{n}} f_{\tilde{n}}\left(s^{\tilde{n}}\right) \leq$ $p \alpha^{n}\left(f_{n}\left(s^{n}\right)-f_{\tilde{n}}\left(s^{\tilde{n}}\right)\right) \leq p \alpha^{n} c s^{n-\tilde{n}}=\frac{p c(\alpha s)^{n}}{s^{\tilde{n}}}$. Then $\varphi_{n}\left(f_{n}\right) \leq \frac{p \alpha^{n} f_{n}\left(s^{n}\right)}{\left|N_{n}\right|} \leq \frac{p \alpha^{\tilde{n}} f_{\tilde{n}}\left(s^{\tilde{n}}\right)(s-1)}{s^{n+1}-1}+$ $\frac{\left(p \alpha^{n} f_{n}\left(s^{n}\right)-p \alpha^{\tilde{n}} f_{\tilde{n}}\left(s^{\tilde{n}}\right)(s-1)\right.}{s^{n+1}-1} \leq \frac{p \alpha^{\tilde{n}} f_{\tilde{n}}\left(s^{\tilde{n}}\right)(s-1)}{s^{n+1}-1}+\frac{p c \alpha^{n}\left(s^{n+1}-s^{n}\right)}{s^{\tilde{n}}\left(s^{n+1}-1\right)} \leq \frac{p \alpha^{\tilde{n}} f_{\tilde{n}}\left(s^{\tilde{n}}\right)(s-1)}{s^{n+1}-1}+\frac{p c \alpha^{n}}{s^{\tilde{n}}}$. So, for $\alpha<1$ it holds that $\lim _{n \rightarrow \infty} \varphi_{n}\left(f_{n}\right)=0$, and thus $\left\{n \in \mathbb{N} \mid \varphi_{n}\left(f_{n}\right) \geq w\right\}$ is bounded for $w>0$, and so is $N(w, \pi, p)$. 
Proposition 3.2 immediately yields the following fundamental result.

Corollary 3.3 (Existence of a finite optimal coordination level) Under the assumptions of Proposition 3.2 the optimal coordination level is finite.

Note that without a finite optimal coordination level our model would not be suitable. In Proposition 3.2 we stated conditions under which the set $N(w, \pi, p)$ is bounded. However, it can still be disconnected or empty (see Figures 3 and 4 ).
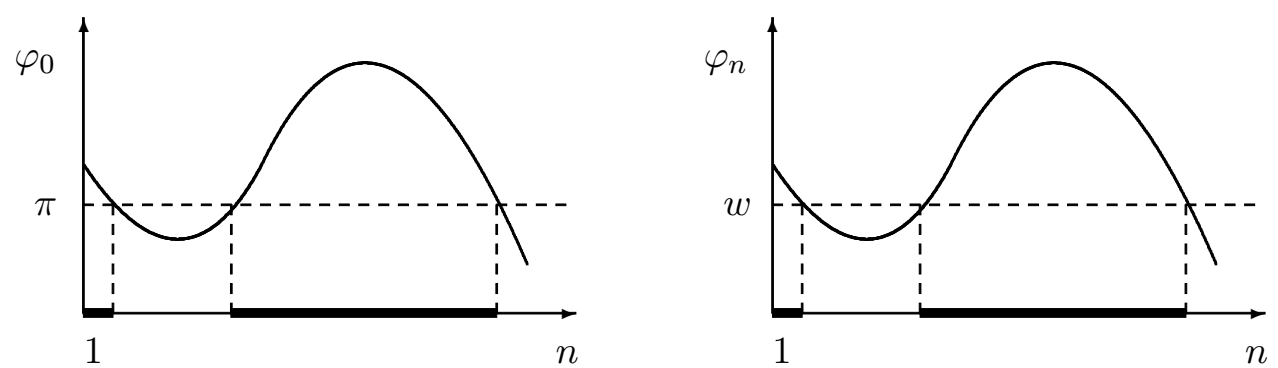

Figure 3: $N(w, \pi, p) \neq \emptyset$ but disconnected.
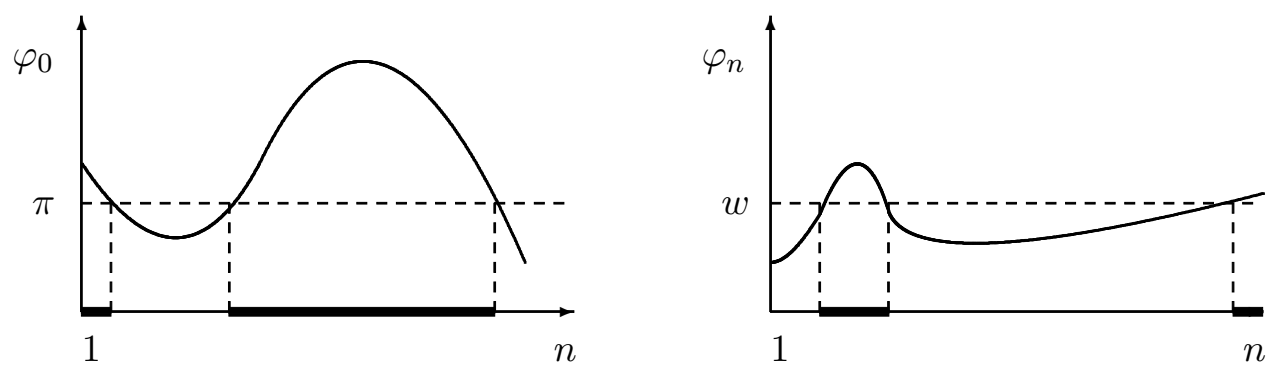

Figure 4: $N(w, \pi, p)=\emptyset$.

\section{A specification: CES production technologies and the per- mission value}

As argued in the previous section, the set $N(w, \pi, p)$ can be empty. Clearly, it is non-empty if profit and wages for a one level firm exceed the corresponding reservation values. In this section we give examples of firms for which $N(w, \pi, p)$ is non-empty. In these examples we use constant elasticity of substitution (CES) production technologies and a specific pay system, namely the permission value. 


\subsection{The permission value}

An example of a pay system satisfying budget neutrality, vertical monotonicity and symmetry is the permission value, developed in a game theoretic context by Gilles, Owen and van den Brink (1992), van den Brink and Gilles (1996) and van den Brink (1997), and applied as a wage schedule in a firm of given size by van den Brink (1996). This implies that the distribution of value added among the owner (as profit) and the employee positions (as wages) depends on the value added that can be generated by all subsets of front-positions $E \subset W_{n}$, i.e., all values $v^{f_{n}}(E)=p \alpha^{n} f_{n}(|E|)$ for $E \subset N_{n}$.

Given the value added $v^{f_{n}}(E)=p \alpha^{n} f(|E|)$ that can be generated by all subsets of frontpositions $E \subset W_{n}$, we define the dividends of subsets of front-positions, recursively, by $\Delta^{f_{n}}(E)=v^{f_{n}}(E)$ if $|E|=1$, and $\Delta^{f_{n}}(E)=v^{f_{n}}(E)-\sum_{\substack{F \subset E \\ F \neq E}} \Delta^{f_{n}}(F)$, otherwise. These dividends can be seen as the productivity of the subsets $E \subset W_{n}$, i.e. the dividend $\Delta^{f_{n}}(E)$ represents the contribution to value added that is generated by $E$ and was not already generated by the subsets of $E$. Note that these dividends can be negative, even for supermodular outcome functions. For a discussion of these dividends we refer to Harsanyi (1959).

Now, the permission value $\widetilde{\varphi}$ distributes the dividend of a set of front-positions $E$ equally among the front-positions in $E$ and their superior positions. Thus, the profit of the owner position and the wages of the employee positions are given by

$$
\widetilde{\varphi}_{i}\left(f_{n}\right)=\sum_{\substack{E \subset W_{n} \\ \widehat{S}_{n}(i) \cap E \neq \emptyset}} \frac{\Delta^{f_{n}}(E)}{\left|\widehat{S}_{n}^{-1}(E)\right|} \text {, for all } i \in N_{n},
$$

where for every $i \in N$ we have $j \in \widehat{S}_{n}(i)$ if and only if $i=j$ or there exists a sequence of positions $\left(h_{1}, \ldots, h_{t}\right)$ such that $h_{1}=i, h_{k+1} \in S\left(h_{k}\right)$ for all $1 \leq k \leq t-1$ and $h_{t}=j$. In other words, $\widehat{S_{n}}(i)$ consists of $i$ and all its subordinates, i.e. positions that can be reached from $i$ by a directed path going down the hierarchy, and for all $E \subset N_{n}$ we have $\widehat{S}_{n}^{-1}(E):=\bigcup_{i \in E} \widehat{S}_{n}^{-1}(i)$ with $\widehat{S}^{-1}(i):=\{j \in N \mid i \in \widehat{S}(j)\}$ being the superiors of $i$. Motivations for using the permission value can be found in van den Brink (1996). It is easy to verify that the permission value satisfies symmetry, and thus the permission value of the worker positions at level $n$ can be indicated by $\widetilde{\varphi}_{n}\left(f_{n}\right)=\widetilde{\varphi}_{i}\left(f_{n}\right)$, for all $i \in W_{n}$. The permission value also satisfies budget neutrality and structural monotonicity, so Proposition 3.2 is valid for $\widetilde{\varphi}$. 
Example 4.1 Consider a firm with span of control $s=2$ and with $n=2$ hierarchical coordination levels. The internal organization structure is represented by the left picture in Figure 1.

First, suppose that production takes place according to the linear outcome function $f_{2}(k)=k$ for all $k \in\left\{1, \ldots,\left|W_{2}\right|\right\}=\{1, \ldots, 4\}$. Let $\alpha=0.9$ and $p=1$. Then the value added to be distributed among the owner position, the four front-positions and the two second level positions is given by $v^{f_{2}}\left(W_{2}\right)=(0.9)^{2}\left|W_{2}\right|=3.24$. For the dividends it then holds that $\Delta^{f_{2}}(E)=v^{f_{2}}(E)$ equals 0.81 if $|E|=1$, and equals 0 otherwise. The wage of a front-position $i \in W_{2}$ is given by $\widetilde{\varphi}_{2}\left(f_{2}\right)=\frac{0.81}{\left|\widehat{S}^{-1}(i)\right|}=\frac{0.81}{3}=0.27$. The wage of a second level position $i$ is given by $\sum_{j \in S(i)} \frac{0.81}{\left|\widehat{S}^{-1}(j)\right|}=\frac{2}{3}(0.81)=0.54$. Finally, the profit of the owner position is given by $\widetilde{\varphi}_{0}\left(f_{2}\right)=\sum_{i \in W_{2}} \frac{0.81}{\left|\widehat{S}^{-1}(i)\right|}=\frac{4}{3}(0.81)=1.08$. Since the sum of all wages and profit equals $1.08+2(0.54)+4(0.27)=3.24$ we have exactly distributed the value added $v^{f_{2}}\left(W_{2}\right)$ among the firm positions.

Next, suppose that production takes place according to the nonlinear (increasing returns to scale) outcome function $f_{2}(k)=k^{2}$ for all $k \in\{1, \ldots, 4\}$. Let $\alpha=1.0$ and $p=1$. Then the total value added to be distributed is given by $v^{f_{2}}\left(W_{2}\right)=(1.0)^{2}\left|W_{2}\right|^{2}=16$. The dividends then are given by:

\begin{tabular}{l|l|r|r|r}
$|E|$ & 1 & 2 & 3 & 4 \\
\hline$v^{f_{2}}(E)$ & 1 & 4 & 9 & 16 \\
$\Delta^{f_{2}}(E)$ & 1 & $4-2 \cdot 1=2$ & $9-3 \cdot 2-3 \cdot 1=0$ & $16-4 \cdot 0-6 \cdot 2-4 \cdot 1=0$
\end{tabular}

The wage of each front-position $i \in W_{2}$ is then given by $\widetilde{\varphi}_{2}\left(f_{2}\right)=\frac{1}{3} \cdot 1+\frac{1}{4} \cdot 2+\frac{1}{5} \cdot 2 \cdot 2=\frac{49}{30}$. The wage of a second level coordinator position is given by $\frac{1}{3} \cdot 1 \cdot 2+\frac{1}{4} \cdot 2+\frac{1}{5} \cdot 2 \cdot 4=\frac{83}{30}$. The profit of the owner position is given by $\widetilde{\varphi}_{0}\left(f_{2}\right)=\frac{1}{3} \cdot 1 \cdot 4+\frac{1}{4} \cdot 2 \cdot 2+\frac{1}{5} \cdot 2 \cdot 4=\frac{118}{30}$. These payments add up to 16 , which again is equal to value added.

In the previous section we argued that the set $N(w, \pi, p)$ of firm levels that are supported by the external environment of a firm can be empty. For firms with supermodular outcome functions and positional wages given by the permission value, conditions for the existence of a positive optimal level in $N(w, \pi, p)$ follow from the following proposition. 
Proposition 4.2 Let $F$ be a firm with a supermodular outcome function for every $n \in \mathbb{N}$, and the permission value as pay system. For given positive reservation-wage, reservation profit, and product price we have that $1 \in N(w, \pi, p)$ if $\frac{v^{f_{1}\left(W_{1}\right)}}{2 s} \geq w$ and $\frac{v^{f_{1}}\left(W_{1}\right)}{s+1} \geq \pi$.

\section{ProOF}

In van den Brink (1996) it is proved that for supermodular value-production functions with identical workers it holds that $1 \leq \frac{\widetilde{\varphi}_{i}\left(f_{n}\right)}{\varphi_{j}\left(f_{n}\right)} \leq s$ for $i \in M_{n}, j \in S_{n}(i), n \in \mathbb{N}$. Applying this result to such a firm with size $n=1$ yields

$$
\begin{aligned}
& \text { (i) } \widetilde{\varphi}_{1}\left(f_{1}\right)=\frac{v^{f_{1}}\left(W_{1}\right)-\widetilde{\varphi}_{0}\left(f_{1}\right)}{s} \geq \frac{v^{f_{1}}\left(W_{1}\right)-s \widetilde{\varphi}_{1}\left(f_{1}\right)}{s} \geq \frac{v^{f_{1}}\left(W_{1}\right)}{2 s} \text {, and } \\
& \text { (ii) } \widetilde{\varphi}_{0}\left(f_{1}\right)=v^{f_{1}}\left(W_{1}\right)-s \widetilde{\varphi}_{n}\left(f_{1}\right) \geq v^{f_{1}}\left(W_{1}\right)-s \widetilde{\varphi}_{0}\left(f_{1}\right) \geq \frac{v^{f_{1}}\left(W_{1}\right)}{s+1} \text {. }
\end{aligned}
$$

\subsection{CES production technologies}

Now we consider a firm which production technology is given by a constant elasticity of substitution (CES) outcome function $f_{n}^{\rho}:\left\{1, \ldots, s^{n}\right\} \rightarrow \mathbb{R}_{+}$given by ${ }^{14}$.

$$
f_{n}^{\rho}(k)=\gamma^{f_{n}^{\rho}}(k)^{\frac{1}{\rho}}, 0<\rho \leq 1
$$

Note that these are supermodular production functions. Although for firms with different size the domain of the outcome function is different, the production technology is the same for all levels of coordination. (For example, a firm producing according to a linear production technology will do so for every size $n$.)

In the previous section we assumed labor productivity per worker to be non-increasing in firm size $n$. The parameter $\gamma_{n}^{\rho}$ is a scale parameter and will be used as a normalization factor in order to keep labor productivity per worker constant for different number of levels $n$, i.e., we assume labor productivity per worker to be independent of firm size. More specifically, in all examples, the normalization factor $\gamma_{n}^{f_{n}^{\rho}}$ is chosen such that production per worker is equal to one for every firm size $n$. By doing this the optimal firm size is not influenced by changes in

\footnotetext{
${ }^{14} \mathrm{~A}$ heterogeneous outcome function is a CES production function with $m$ inputs if it is given by $f(x)=$ $\gamma\left(\sum_{i=1}^{m}\left(x_{i}\right)^{\rho}\right)^{\frac{1}{\rho}}, x \in \mathbb{R}^{m}, \gamma \in \mathbb{R}, \rho \in(-\infty, 1]$. Here we adapt this type of function for the homgeneous firm considered in this paper.
} 
labor productivity. Note that this does not imply that the optimal firm size $n$ is independent of the production technology $f$ since the distribution of the value added among the owner (as profit) and the employee positions (as positional wages) depends on the value added that can be generated by subsets of front-positions $E \subset W_{n}$, i.e., all values $v^{f_{n}^{\rho}}(E)=p \alpha^{n} f_{n}^{\rho}(|E|)$. Since we assume the outcome function to be monotone $\rho$ should be positive.

An $n$-level firm with all positions occupied produces $f_{n}^{\rho}\left(s^{n}\right)=\gamma^{f_{n}^{\rho}} s^{n / \rho}$, with value added given by $v^{f_{n}^{\rho}}\left(W_{n}\right)=p \alpha^{n} \gamma^{f_{n}^{\rho}} s^{n / \rho}$. Note that the propositions of the previous section are valid for these CES production firms.

We consider three special cases with respect to $\rho$ : the linear production technology with $\rho=1$, the Cobb-Douglas technology with $\rho \rightarrow 0$, and an intermediate technology with $\rho=\frac{1}{2}$. In the following we assume for simplicity that the level $n$ can be any non-negative real number, i.e., $n \in \mathbb{R}_{+}$.

\subsubsection{Linear outcome functions: separable working labor}

In case $\rho=1$ we have a linear production technology with outcome function $f_{n}^{1}(k)=\gamma^{f_{n}^{1}} k$. In this case, which coincides with Williamson (1967), the labor inputs are substitutes. Since $f_{n}^{1}\left(s^{n}\right)=\gamma^{f_{n}^{1}} s^{n}$, it must hold that $\gamma_{n}^{f_{n}^{1}}=1$ (since the normalization factor $\gamma^{f_{n}^{1}}$ is such that production per worker is equal to 1). The value added of a firm with front-positions $E \subset W_{n}$ occupied then is given by

$$
v^{f_{n}^{1}}(E)=p \alpha^{n}|E|, \text { for all } E \subset W_{n} .
$$

In this case profit equals

$$
\widetilde{\varphi}_{0}\left(f_{n}^{1}\right)=\frac{p(\alpha s)^{n}}{n+1}
$$

In the following we first assume that $\widetilde{\varphi}_{0}\left(f_{1}^{0}\right) \geq \pi$. The workers will only accept the positions offered to them if the corresponding positional wages exceed their reservation wages. The wage assigned to front-position $i \in W_{n}$ in an $n$-level firm is given by

$$
\widetilde{\varphi}_{n}\left(f_{n}^{1}\right)=\frac{p \alpha^{n}}{n+1} .
$$


Assume for simplicity that the level $n$ can be any non-negative real number, i.e., $n \in \mathbb{R}_{+}$. Since $\ln (\alpha)<0$ (because $\alpha<1$ ) it holds that

$$
\frac{d \widetilde{\varphi}_{n}\left(f_{n}^{1}\right)}{d n}=\frac{\alpha^{n}((n+1) \ln (\alpha)-1)}{(n+1)^{2}}<0,
$$

and thus the wage assigned to the front-positions is decreasing with the firm size $n$ (see the right picture in Figure 5).
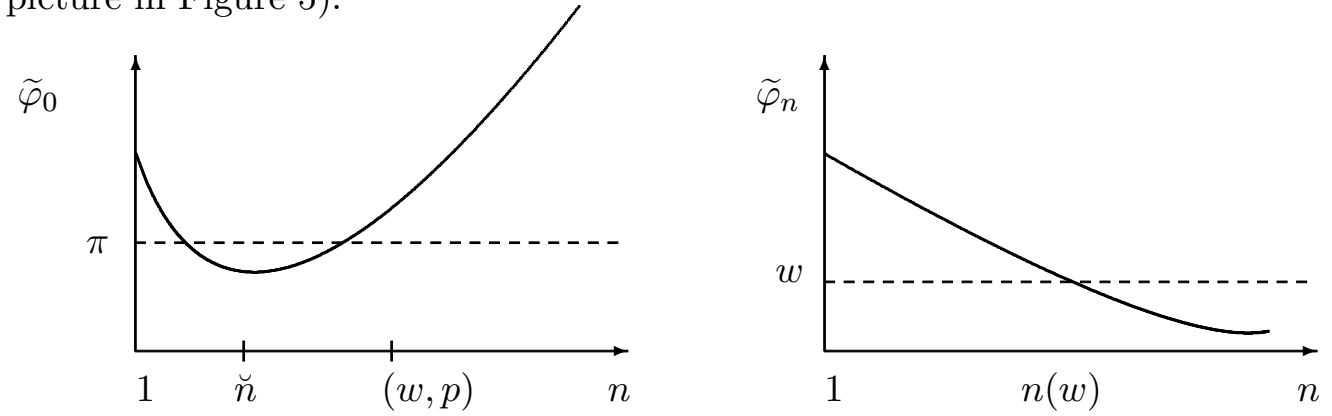

Figure 5: Profit and wages for a linear production technology.

For the moment we ignore the owner participation constraint. Clearly, in this case the set $N(w, 0, p)$ is connected and bounded from above by the reservation wage level $n(w)$ defined as the level of coordination above which the wage of workers is lower than their reservation wage, $w$, i.e., $n(w)=\max \left\{n \in \mathbb{R}_{+} \mid \widetilde{\varphi}_{n}\left(f_{n}\right) \geq w\right\}$. So, $N(w, 0, p)=[0, n(w)]$. The reservation wage level is the deepest internal organization structure that the labor market will bear and is given by

$$
n(w)=\max \left\{n \in \mathbb{R}_{+} \mid \frac{p \alpha^{n}}{n+1} \geq w\right\} .
$$

The optimal size of the firm is determined by maximizing the profit (see equation (2)) of the owner:

$$
\frac{d \widetilde{\varphi}_{0}\left(f_{n}^{1}\right)}{d n}=\frac{p(\alpha s)^{n}((n+1) \ln (\alpha s)-1)}{(n+1)^{2}}=0
$$

so

$$
n=\frac{1}{\ln (\alpha s)}-1
$$

It may be noticed that $\alpha s>0$, otherwise there would be no reason to expand. For $n=$ $\frac{1}{\ln (\alpha s)}-1$, the second order conditions are:

$$
\left.\frac{d^{2} \widetilde{\varphi}_{0}\left(f_{n}^{1}\right)}{d n^{2}}\right|_{n=\frac{1}{\ln (\alpha s)}-1}=\frac{(p \alpha s)^{n}\left(((n+1) n \ln (\alpha s))^{2}-2(n+1) \ln (\alpha s)+2\right)}{n^{3}}>0 .
$$


Thus, $\widetilde{\varphi}_{0}\left(f_{n}^{1}\right)$ attains its minimum at

$$
\breve{n}=\frac{1}{\ln (\alpha s)}-1
$$

Thus, the profit function $\widetilde{\varphi}_{0}\left(f_{n}^{1}\right)$ decreases to a minimum (attained at $\breve{n}$ ) and then increases monotonically (see the left picture in Figure 5). This implies that from the critical level $(w, p)=\min \left\{n>0 \mid \widetilde{\varphi}_{0}\left(f_{n}\right)=\bar{\varphi}_{0}(n)\right\}$, being the minimal size for which profit is at least as high as profit for a firm of size 1, there is no limit to firm size from the point of view of the owner, and thus the owner will try to expand the firm size indefinitely due to its profit maximizing behavior. The owner, however, is restricted in this ambition by the labor market, i.e., the optimal firm size $n^{*}$ should be an element of $N(w, 0, p)$ determined above.

Next we discuss how the optimal level $n^{*}$ looks like. If $\widetilde{\varphi}_{0}\left(f_{n(w)}^{1}\right)>\widetilde{\varphi}_{0}\left(f_{1}^{1}\right)$ then the reservation wage level $n(w)$ exceeds the critical level $(w, p)$. In that case the owner will set the depth of the internal organization to the reservation level, $n(w)$, and, implicitly, will reduce the wage of the workers as close to their reservation wage as possible. Thus, it are the workers who determine the depth of the firm.

However, if $\widetilde{\varphi}_{0}\left(f_{n(w)}^{1}\right) \leq \widetilde{\varphi}_{0}\left(f_{1}^{1}\right)$, and thus $n(w) \leq(w, p)$, then coordination is not profitable. If $\widetilde{\varphi}_{n}\left(f_{1}^{1}\right) \geq w$ the firm will have only one hierarchical level with no intermediate coordinators. If $\widetilde{\varphi}_{n}\left(f_{1}^{1}\right)<w$ then the firm will not be active.

Above we ignored the participation constraint of the owner. Also considering that constraint, the above is still valid as long as $\max \left\{\widetilde{\varphi}_{0}\left(f_{1}^{1}\right), \widetilde{\varphi}_{0}\left(f_{n(w}^{1}\right)\right\} \geq \pi$. Of course, $n=0$ if $\max \left\{\widetilde{\varphi}_{0}\left(f_{1}^{1}\right), \widetilde{\varphi}_{0}\left(f_{n(w}^{1}\right)\right\} \leq \pi$.

If $\frac{1}{\ln (\alpha s)}-1 \leq 1$ the profit of the owner attains its minimum at $\breve{n} \leq 1$ and profits are monotonically increasing in $n \geq 1$. In this case the owner will always push the workers to their reservation wages, and set the number of hierarchical levels of the firm equal to $n(w)$. Note that $\breve{n}=\frac{1}{\ln (\alpha s)}-1 \leq 1$ if and only if $\alpha s \geq e^{\frac{1}{2}} \simeq 1.65$. For $s=2$ this means that $\widetilde{\varphi}_{0}$ is increasing in $n$ for $\alpha \geq 0.825$. For $s>2$ this is even the case for lower values of $\alpha$. Williamson (1967) argues that $\alpha$ mostly will be in the neighborhood of 0.9 . So, we might expect $\widetilde{\varphi}_{0}$ to be increasing in $n$, and the depth of the firm to be determined by the reservation wages of the workers. Summarizing 
Proposition 4.3 (Linear outcome functions) Let the firm given in Proposition 3.2 have a linear production technology, i.e., $\rho=1$. If $\widetilde{\varphi}_{0}\left(f_{1}^{1}\right) \geq \pi, \widetilde{\varphi}_{n}\left(f_{1}^{1}\right) \geq w$ and $\alpha s \geq 1.65$, then profit is monotonically increasing in firm size $n \geq 1$ and the owner will choose the deepest organization structure $n^{*}=n(w)$ restricted by the reservation wage of the workers. In that case worker wages $w^{*}=\widetilde{\varphi}_{n^{*}}\left(f_{n^{*}}^{1}\right)$ are as close to the reservation wage $w$ as possible, and employment in the firm is equal to $\left|N_{n^{*}}\right|=\sum_{k=0}^{n^{*}} s^{k}=\left(s^{n^{*}+1}-1\right) /(s-1)$.

If $\widetilde{\varphi}_{0}\left(f_{1}^{1}\right) \geq \pi$ and $\widetilde{\varphi}_{n}\left(f_{1}^{1}\right) \geq w$ but $\alpha s<1.65$ then the owner chooses the deepest organization $n^{*}=n(w)$ only if $\widetilde{\varphi}_{0}(n(w))=\bar{\varphi}_{0}(n(w))$. Otherwise the flattest organization structure $n^{*}=1$ is chosen. Finally, the firm is inactive if $\widetilde{\varphi}_{0}\left(f_{1}^{1}\right)<\pi$ or $\widetilde{\varphi}_{n}\left(f_{1}^{1}\right)<w$.

Example 4.4 (Low agency cost) Let $s=2, p=1$, and $\alpha=0.9$. In Table 1 we give some values for $\widetilde{\varphi}_{0}\left(f_{n}^{1}\right)$ and $\widetilde{\varphi}_{n}\left(f_{n}^{1}\right)$. (Note that $n=2$ coincides with the linear production firm of Example 4.1.)

\begin{tabular}{|c||c|c|c|}
\hline $\mathrm{n}$ & $\widetilde{\varphi}_{0}\left(f_{n}^{1}\right)$ & $\widetilde{\varphi}_{n}\left(f_{n}^{1}\right)$ & critical level \\
\hline 1 & 0.900 & 0.450 & $(w, p)$ \\
2 & 1.080 & 0.270 & \\
3 & 1.458 & 0.182 & \\
4 & 2.100 & 0.131 & \\
5 & 3.149 & 0.098 & \\
\hline
\end{tabular}

Table 1: $\rho=1, s=2, \alpha=0.9, p=1$

From this table it follows that if, for example, $w=\pi=0.15$ then firm size will be equal to 3 .

Example 4.5 (High agency cost) Next, choose $s=2, p=1$, but let $\alpha=0.7$. Table 2 gives the values for $\widetilde{\varphi}_{0}\left(f_{n}^{1}\right)$ and $\widetilde{\varphi}_{n}\left(f_{n}^{1}\right)$.

Thus, the profit of the firm is minimal for $\breve{n}=2$. If, again, $w=\pi=0.15$ then the workers will only accept a position in a firm with $n \leq 2$. In that case the owners will form the flattest hierarchical structure, and thus the firm will have one level.

If, for example, $w=0.03$ then, similarly as in Example 3.2, the owners of the firm will push the workers to their reservation wages and set firm size equal to 4 . 


\begin{tabular}{|c||c|c|c|}
\hline $\mathrm{n}$ & $\widetilde{\varphi}_{0}\left(f_{n}^{1}\right)$ & $\widetilde{\varphi}_{n}\left(f_{n}^{1}\right)$ & critical level \\
\hline 1 & 0.700 & 0.350 & \\
2 & 0.653 & 0.163 & \\
3 & 0.686 & 0.086 & \\
4 & 0.768 & 0.048 & $(w, p)$ \\
5 & 0.896 & 0.028 & \\
\hline
\end{tabular}

Table 2: $\rho=1, s=2, \alpha=0.7, p=1$

Example 4.6 The third case is based on values for the parameters suggested by Williamson (1967). He argues that the normal range for $s$ is between 5 and 10. Now, let $s=6, p=1$, and $\alpha=0.9$. In Table 3 we give some values for $\widetilde{\varphi}_{0}\left(f_{n}^{1}\right)$ and $\widetilde{\varphi}_{n}\left(f_{n}^{1}\right)$, in this case.

\begin{tabular}{|c||c|c|c|}
\hline $\mathrm{n}$ & $\widetilde{\varphi}_{0}\left(f_{n}^{1}\right)$ & $\widetilde{\varphi}_{n}\left(f_{n}^{1}\right)$ & critical level \\
\hline 1 & 2.7 & 0.450 & $(w, p)$ \\
2 & 9.7 & 0.270 & \\
3 & 39.37 & 0.182 & \\
4 & 170.061 & 0.131 & \\
5 & 765.275 & 0.098 & \\
\hline
\end{tabular}

Table 3: $\rho=1, s=6, \alpha=0.9, p=1$

From this table it follows that if, for example, $w=\pi=0.15$ then firm size again will be equal to 3. (Note that for linear production technologies the wage of the worker positions in the lowest level is independent of the span of control $s$. Therefore worker wages are the same as in Table 1 and firm size is the same as in the first example.) Again the workers are pushed to their reservation wages.

\subsubsection{Cobb-Douglas outcome functions: indispensable working labor}

If $\rho$ approaches 0 then $f^{\rho}$ approaches a Cobb-Douglas outcome function $f_{n}^{0}:\left\{1, \ldots, s^{n}\right\} \rightarrow \mathbb{R}_{+}$ given by $f_{n}^{0}(k)=\gamma^{f_{n}^{0}} 1^{k} 0^{s^{n}-k}=\left\{\begin{array}{cl}\gamma^{f_{n}^{0}} & \text { if } k=s^{n} \\ 0 & \text { otherwise. }\end{array}\right.$

Since $f_{n}^{0}\left(s^{n}\right)=\gamma^{f_{n}^{0}}$ the normalization factor is $\gamma_{n}^{f_{n}^{0}}=s^{n}$. In this case value added is given 
by

$$
v^{f_{n}^{0}}(E)=\left\{\begin{array}{cl}
p(\alpha s)^{n} & \text { if } E \supset W_{n} \\
0 & \text { else, }
\end{array}\right.
$$

i.e., if all positions in the $n$-level firm are occupied then value added equals $p(\alpha s)^{n}$, while value added equals zero if at least one position is not occupied. This reflects the indispensability of the working labor inputs. In this case the profit of the owner is given by

$$
\widetilde{\varphi}_{0}\left(f_{n}^{0}\right)=\frac{p(\alpha s)^{n}}{\sum_{k=0}^{n} s^{k}}=\frac{p(\alpha s)^{n}(s-1)}{\left(s^{n+1}-1\right)} .
$$

Similar as for linear production technologies we assume that $\widetilde{\varphi}_{0}\left(f_{1}^{0}\right) \geq \pi$. Again assume for simplicity that the level $n$ can be any non-negative real number. Since $\ln (\alpha)<0$, i.e., $\alpha<1$, and $\ln (\alpha s)>0$, i.e., $\alpha s>1$, it holds that

$$
\frac{d \widetilde{\varphi}_{0}\left(f_{n}^{0}\right)}{d n}=\frac{p(\alpha s)^{n}(s-1)\left(s^{n+1} \ln (\alpha)-\ln (\alpha s)\right)}{\left(s^{n+1}-1\right)^{2}}<0 .
$$

Thus, profits are decreasing in the number of hierarchical levels. It follows that the owner sets firm size $n$ not higher than 1, the flattest possible structure. For the workers $i \in W_{n}$ it holds that $\widetilde{\varphi}_{n}\left(f_{n}^{0}\right)=\widetilde{\varphi}_{0}\left(f_{n}^{0}\right)$. So, they accept the positions in the firm if $\frac{p \alpha s(s-1)}{s^{2}-1} \geq w$. In this case it are the owners of the firm who determine the firm structure $n=1$. For fixed $\alpha$ and $n$ the wage of the workers is higher as compared to the linear production case. For the individual workers who occupy a position in the firm this is the best possible structure.

Proposition 4.7 (Cobb-Douglas outcome function) Let the firm given in Proposition 3.2 have a Cobb-Douglas production technology, i.e., $\rho \rightarrow 0$. If $\widetilde{\varphi}_{0}\left(f_{1}^{0}\right) \geq \pi$ and $\widetilde{\varphi}_{n}\left(f_{1}^{0}\right) \geq w$, then the owner will choose the flattest organization $n^{*}=1$, and wages equal profit. In that case employment in the firm is equal to $\left|N_{n^{*}}\right|=s+1$.

If $\widetilde{\varphi}_{0}\left(f_{1}^{0}\right)<\pi$ or $\widetilde{\varphi}_{n}\left(f_{1}^{0}\right)<w$ then the firm is inactive.

Example 4.8 Let $p=1, \alpha=0.7$, and $s=2$. In Table 4 we give some values for $\widetilde{\varphi}_{0}\left(f_{n}^{0}\right)$ and $\widetilde{\varphi}_{n}\left(f_{n}^{0}\right)$.

If $w, \pi \leq 0.467$ the firm will have one hierarchical level. Otherwise the firm will not be active. 


\begin{tabular}{|c|c|c|}
\hline $\mathrm{n}$ & $\widetilde{\varphi}_{0}\left(f_{n}^{0}\right)=\widetilde{\varphi}_{n}\left(f_{n}^{0}\right)$ & critical level \\
\hline 1 & 0.467 & \\
2 & 0.280 & \\
3 & 0.183 & \\
4 & 0.124 & \\
5 & 0.085 & \\
$\cdot$ & & \\
$\infty$ & 0.000 & $(w, p)$ \\
\hline
\end{tabular}

Table $4: \rho \rightarrow 0, s=2, \alpha=0.7, p=1$

\subsubsection{An intermediate case}

For the linear production technology we saw that $\breve{n}<1$ for reasonable values of $\alpha$ and $s$, and firm size is determined by the reservation wage of the workers. For the Cobb-Douglas production technology we saw that firm size is always equal to 1 (or 0 ). For values of $\rho$ between 0 and 1 both cases can occur. Whether firm size is determined by the reservation wage of the workers or set equal to 1 depends on the values of $\alpha$ and $s$.As an illustration consider the case $\rho=\frac{1}{2}$. Then the outcome function is given by $f_{n}^{1 / 2}(k)=\gamma^{f_{n}^{1 / 2}} k^{2}, k \in\left\{0, \ldots, s^{n}\right\}$. Since $f_{n}^{1 / 2}\left(s^{n}\right)=\gamma^{f_{n}^{1 / 2}} s^{2 n}$, the normalization factor is $\gamma^{f_{n}^{1 / 2}}=\frac{1}{s^{n}}$. The value added then is given by

$$
v^{f_{n}^{1 / 2}}(E)=p\left(\frac{\alpha}{s}\right)^{n}|E|^{2}, \text { for all } E \subset W_{n} .
$$

For convenience we only consider the case with $s=2$. In this case profit equals

$$
\widetilde{\varphi}_{0}\left(f_{n}^{1 / 2}\right)=p \alpha^{n}\left(\frac{1}{n+1}+\sum_{k=0}^{n-1} \frac{2^{k}}{(n+k+2)}\right)
$$

and the wage of the workers $i \in W_{n}$ equals

$$
p \widetilde{\varphi}_{n}\left(f_{n}^{1 / 2}\right)=\alpha^{n}\left(\sum_{k=0}^{n} \frac{1}{(n+k+1) 2^{n-k}}\right) .
$$

Similarly to the linear production case, the profit decreases to a minimum (attained at $\breve{n}$ ), and then increases with $n$. The value of $\breve{n}$ depends on the value of the parameter $\alpha$. Compared to the linear production technology, for fixed $\alpha$ the minimum in this intermediate case is reached for a higher value of $n$. Moreover, for fixed $\alpha$ and $n$ the wage assigned to the worker positions in this intermediate case lies between the wage in the linear production firm and the Cobb-Douglas firm. 
Example 4.9 Let $s=2, p=1$, and $\alpha=0.7$. In Table 6 we give some values for $\widetilde{\varphi}_{0}\left(f_{n}^{1 / 2}\right)$ and $\widetilde{\varphi}_{n}\left(f_{n}^{1 / 2}\right)$. (Compare to Table 2 for the linear production technology and Table 5 for the Cobb-Douglas technology.)

\begin{tabular}{|c||c|c|c|}
\hline $\mathrm{n}$ & $\widetilde{\varphi}_{0}\left(f_{n}^{1 / 2}\right)$ & $\widetilde{\varphi}_{i}\left(f_{n}^{1 / 2}\right)$ & critical level \\
\hline 1 & 0.583 & 0.408 & \\
2 & 0.482 & 0.200 & \\
3 & 0.465 & 0.105 & \\
4 & 0.490 & 0.058 & \\
5 & 0.548 & 0.033 & \\
6 & 0.637 & 0.020 & $(w, p)$ \\
7 & 0.762 & 0.010 & \\
\hline
\end{tabular}

Table 5: $\rho=\frac{1}{2}, s=2, \alpha=0.7, p=1$

Thus, the profit of the firm is minimal for $n=3$. If $w=\pi=0.15$ then the workers will only accept a position in a firm with $n \leq 2$. In that case the owners will set firm size equal to 1 if the resevation profit $\pi$ allows to do so. If, for example, $w=0.015$ then the owner of the firm will push the wage of the workers to their reservation wages and set firm size equal to 6 . Compared to Table 2 we see that the minimal profit is reached for a higher value of $n$.

Besides the substitutability of the labor inputs the value of $\breve{n}$ (and thus $(w, p)$ ) is also determined by the value of the parameter $\alpha$. A low value of $\alpha$ (high agency costs) yields a high value of $\breve{n}$, and thus there is a wide range of production technologies for which firm size is equal to 1 and the reservation wage of the workers does not influence firm size. If $\alpha$ increases, i.e., agency costs decrease, $\breve{n}$ decreases, and it can be that the owners push the workers to their reservation wage. In that case firm size, and thus employment, is influenced by the reservation wage of the workers. 


\section{Discontinuity of the firms demand and supply functions and the Institutional Market Equilibirum}

Ruys and van den Brink (1999) introduce an Institutional Market Economy as a triple $E=$ $(F, \mathcal{C}, \mathcal{M})$, consisting of a representative firm $F$, a finite set of consumers ${ }^{15} \mathcal{C}$ and a finite set of competitive markets $\mathcal{M}$. An owner can activate a firm only by means of the resources obtained from the markets and the firm's value added is also determined by markets transactions.

The internal equilibrium of the representative firm, i.e., the optimal level of its organization, has been determined as a function $n: \mathbb{R}_{+}^{3} \rightarrow \mathbb{R}$ with $n(w, \pi, p)$ the optimal firm level for wage $w$, rate of return on capital $r$ and output price $p$. Now, the reservation prices in the previous sections are replaced by the market prices, i.e. the reservation wage is determined by the market wage, the reservation profit is determined by the rate of return on capital and the output price is determined by the market price of the consumption good.

The demand for labor, $d_{l}$, and the supply of commodities, $s_{c}$, are functions of the market prices, $d_{l}(w, \pi, p)=\frac{s^{n(w, \pi, p)+1}-1}{s-1}-1$, and $s_{c}(w, \pi, p)=(\alpha s)^{n(w, \pi, p)}$ for any triple of market prices $w, \pi$ and $p$, as in Section 2. The capital needed for each active firm is equal to 1 . Market demand and supply is determined by assuming that all firms are identical. So the firm is a representative firm in the industry, which may consist of more than one firm. The number of firms is set equal to the capital demanded on the market. Assuming market supply of capital to be inelastic and given by $\bar{k} \in \mathbb{N}$, the number of firms on the market is then equal to $m=\bar{k}$. Assume that the rate of return on capital $\pi$ is small enough to have no impact on the decision by the owner to activate the firm. Then only the relative prices between $p$ and $w$ matter.

Given an arbitrary pair of prices $p$ and $w$ we can determine the optimal size $n(w, p)$ of the firm by maximizing positional return on capital (with value added evaluated at price $p$ ) under the worker-participation constraint (determined by wage $w$ ) as done before. Market supply of the consumption good and market demand for labor then are given by $S_{c}(w, p)=m s^{n(w, p)}$, respectively, $D_{l}(w, p)=m\left(\frac{s^{(n(w, p)+1)}}{s-1}-1\right)$.

\footnotetext{
${ }^{15}$ Since in this paper the household is not incorporated, the neoclassical concept of a consumer is used. For the definition of an incorporated household see Ruys, Semenov and van den Brink (1998).
} 
The consumer side of the market consists of a set of consumers $\mathcal{C}$, each consumer $i \in \mathcal{C}$ having an initial endowment $\bar{c}_{i} \in \mathbb{R}_{+}$of the consumption good, $\bar{l}_{i} \in \mathbb{R}_{+}$units of time to spend as leisure or labor supply in a firm, and preferences over leisure and the consumption good represented by a utility function $u^{i}: \mathbb{R}_{+}^{2} \rightarrow \mathbb{R}$. Assuming consumer preferences to satisfy the standard regularity conditions, this yields market demand for the consumption good and market supply of labor as functions of $p$ and $w$. That determines consumer demand and supply on markets, $D_{c}(w, p)$ and $S_{l}(w, p)$.

Confronting market supply and market demand at given prices $p$ and $w$, there may exist equilibrium prices $p^{*}$ and $w^{*}$, defined as follows.

Definition 5.1 An Institutional Market Equilibrium in an Institutional Market Economy $E$ is a pair of prices, $(p, w)$, and an institutional activity level, $n$, such that:

1. $n$ is the optimal firm level, i.e., $n=n(w, p)$ and

2. $p, w$ are competitive equilibrium prices at which market supply equals market demand.

The optimal activity level of a firm determined at non-equilibrium prices will distort some market supply or demand, whereas prices at equal market demand and supply, called provisional equilibrium prices, may cause adaptations within the firm and thus change market demand and supply. Only when the external competitive equilibrium prices are consistent with the firms' internal equilibrium, the economy is in a state of equilibrium.

Let some market prices $(w, p)$ be given to the firm, leading to provisional equilibrium prices $\left(w^{*}, p^{*}\right)$. Of course, it may not be the case that these provisonal equilibrium prices are equal to the provisional market prices we started with. The question arises whether the internal adaptation process supports or counteracts the external adaptation process. Ruys and van den Brink (1999) show that an institutional market equilibrium exists if $n$ is continuous in prices $^{16}$.

Determining equilibrium prices in case the production technology is a Cobb-Douglas technology with complementary labor inputs we only have to consider firm size $n=1$ since that

\footnotetext{
${ }^{16}$ Since high reservation wages will only support small firm size it holds that $n(w, p) \rightarrow 0$ if $\frac{w}{p} \rightarrow \infty$. On the other hand, low reservation wages result in large firm size since positional return on capital is increasing in $n$ for large enough $n$ (and $\rho \in(0,1]$ ), and thus $n(w, p) \rightarrow \infty$ if $\frac{w}{p} \rightarrow 0$.
} 
is the optimal size for an active firm for all prices, see Section 4.2.2. If positional return on capital is positive at the equilibrium output price and $\varphi_{n}\left(f_{n}\right)$ exceeds the equilibrium wage at $n=1$, then these equilibrium prices also are institutional market equilibrium prices, and $n=1$ is the institutional market equilibrium firm size. Otherwise, institutional market equilibrium firm size equals $n=0$, with institutional market equilibrium prices such that the workers do not want to activate the firm.

For a firm with a linear production technology (substitutable labor inputs) and $\alpha s \geq e^{\frac{1}{2}}$ an institutional market equilibrium exists since optimal firm size $n$ is continuous in $p$ and $w$, see Section 4.2.1.

However, for intermediate cases of labor complementarity, institutional market equilibrium prices need not exist since optimal firm size $n$ is discontinuous in $w$. This discontinuity occurs if positional return on capital (profit) of a firm with maximal size that can be supported by the equilibrium wage is lower than the positional return on capital of a firm with size equal to one. In the left picture of Figure 5 this is illustrated by a possible jump in firm size from $n=1$ tot $n=(w, p)$.

Summarizing,

Proposition 5.2 In an Institutional Market Economy, $E=(F, \mathcal{C}, \mathcal{M})$, in which the firm produces according to a linear outcome function (with $\alpha s \geq e^{\frac{1}{2}}$ ) or a Cobb-Douglas outcome function (such that average labor productivity is non-increasing with firm size), the optimal firm size $n^{*}$ is continuous in prices $p$ and $w$. For other firms this need not be the case.

As a consequence of this proposition we have that in an Institutional Market Economy an institutional market equilibrium exists if the firm is as described in Proposition 5.2, see Ruys and van den Brink (1999). The institutional market equilibrium concept generalizes upon the competitive equilibrium concept if one assumes that the economy becomes transparant on the long run. In that case the positional rents of cooperation within firms disappear and an overall Pareto efficiency is obtained. 


\section{Related literature}

In this paper we presented a model which endogenously determines the optimal size of the firm. We presented a hybrid model that has cooperative as well as noncooperative features. Our model fits well in new institutional economics which acknowledges that the neoclassical model of a firm, although very useful, is not sufficient to fully understand what happens inside and outside firms. Although it is not primarily about the main topics in new institutional economics, namely transaction costs and bounded rationality, we argue in a similar way as Furutbotn (2001) does that under bounded rationality and transaction costs profit maximization in the neoclassical way is not possible and other criteria have to be considered. In our model of a hierarchically structured firm we assume a wage function that assigns wages to the different positions in the firm to be given, since bounded rationality or transaction costs might prevent the employees to fully know their outside opportunities or have to make high costs in switching jobs or renegotiating every time an improvement can be made.

Assuming that production processes in industries that heavily depend on innovation, usually use more complementary labor, our result that complementary labor inputs lead to flatter hierarchies is in line with Teece (1996). He studies the relation between firm structure and innovation and concludes that firms strongly depending on innovation have correspondingly flatter hierarchies. We also agree with Teece (1996) that the effect of culture on organization is rarely investigated by economists. However, as mentioned before, van den Brink, Ruys and Semenov (1999) and Ruys, van den Brink and Semenov (2000) relate the different parameters of the firm model presented in this paper to different cultural dimensions as introduced by Hofstede (1980).

Our model also is in line with Rajan and Zingales (1998), who focus on the control of access to a productive asset. This in contrast with the literature on incomplete contracts which tries to explain the distribution of residual rights concerning the control over non-contractable assets (see, e.g., Grossman and Hart (1986), Hart and Moore (1990, 1999), and Maskin and

Tirole (1999)), and thus puts ownership of assets central. Similar as in our paper, Rajan and Zingales (2001) try to explain firm formation focussing on the effects of agency costs and benefits on the firm's organization. They address the entrepreneurial problem of enlisting 
the cooperation of many agents necessary for production without ceding to them too much of the surplus generated by the enterprise. The tradeoff for the entrepreneur exists in designing a governance that gives subordinated managers access to the critical resource owned by the entrepreneur, without being expropriated by these managers. They distinguish two ways of giving access. In the horizontal hierarchy, the entrepreneur mediates all interactions within the organization, but - once hired - managers can expropriate the technology and compete with the entrepreneur. In the vertical hierarchy there is a chain of managers who learn, at a cost, to perform the tasks their immediate superior has assigned to them (i.e. specialize). The vertical hierarchy gives some manager positional power by commanding the loyalty of subordinates, which power can be used to compete with the owner. The horizontal hierarchy is effective because the tactic of divide and conquer prevents managers getting positional power. The solution is a dynamic approach in which a manager is induced to specialize and then entrusted with more positional power. A specialized manager is more loyal and becomes part of a "dedicated hierarchy", which is a critical resource in its own right for the entrepreneur. In our model, the key is the internal pay system, in which the entrepreneur's vertical control over a manager's access to the resource, as well as the entrepreneur's horizontal redistribution of the rents to that manager, is in balance. The internal pay of positions in the governance is based on a system of bargaining from bottom up. The relation between asset ownership and relational contracts is studied in Baker, Gibbons and Murphy (2002). Van den Brink and Gilles (2003) also consider hierarchical organizations but look at 'what game is played' within a hierarchy where superiors have the power to veto their subordinates.

In our paper a network consists of principal-agent relations. But since in our model of cooperative team production there is no uncertainty, issues like information problems and moral hazard do not arise. In this sense our model is complementary to the literature on principal-agent theory and moral hazard (see, e.g., Holmström (1979), Grossman and Hart (1983), Kessler (2000)). We can extend our model, for example by introducing risk as done in Prescott and Townsend (2002) who study how risk sharing can be a reason to form collective organizations by using principal-agent relations between these organizations and outsiders. These models mainly use non-cooperative game models to study economic organizations in 
which binding agreements are not possible. Cooperative game theory yields valuable tools when studying cooperative situations in which binding agreements are possible. Recently, the use of cooperative game theory in analyzing economic organizations becomes more popular. Rotschild (2001) uses a solution similar to the Shapley value to determine the allocation of benefits among firms that form a cartel. Curiel (1988), Hamers (1995) and Maniquet (2003) study sequencing situations in which a set of jobs in a queue have to be processed, and in particular use the Shapley value to solve such situations, i.e. determine aan optimal sequence and compensations scheme that compensates jobs that are later in the queue ${ }^{17}$ Ambec and Sprumont (2002) study water distribution problems in which agents that are located along a river from upstream to downstream must decide on an allocation of the water that flows into the river between each pair of agents and compensation for the agents that do not use all their water inflow. Graham, Marshall and Richard (1990) study cooperation among bidders in an (English open bid and Second price sealed bid) auction.

Similar as in, e.g. DeCanio and Watkins (1998) and Garicano (2000), we put aside incentive problems and assumed that if an employee is active in a firm then it is 'fully' productive. As Beggs (2001) argues to get more insight in the functioning of hierarchical organizations it is best to focus on one of many aspects. In this sense these models are complementary to the models which focus on incentive problems such as Qian (1994) who endogenously determines the number of hierarchical levels, the span of control and the wage scales by using optimal control techniques, and in that way extends the seminal work of Keren and Levhari $(1979,1983)$. Wage differences in our model arise not because of incentives, but because of differences in the production technology, which is not considered by Qian (1994).

In the desciption of the firm we took the same approach as in Maskin, Qian and Xu (2000) who state that an organization is a "hierarchy of managers built on top of technology" where the technology is present in productive plants. However, since we assumed a constant span of control, and in the organization structure of the firm only vary the number of levels, we do not study the organizational form of a hierarchy as done by Maskin, Qian and Xu (2000) who

\footnotetext{
${ }^{17}$ In this literature a distinction is made between situations in which the jobs are already ordered in some initial queue as in Curiel (1988) and Hamers (1995), and situations where there is no initial queue as in Maniquet (2003).
} 
compare an M-form (multidivisional form in which the organization goes along institutional lines) with a U-form (unitary form in which the organization goes along regional lines) with respect to their effectiveness in giving incentives to managers.

Beggs (2001) uses optimal control techniques to determine the optimal structure of hierarchies when workers differ in the range of tasks they can perform. He studies how the complexity of tasks influences organizational structure. He explains why many organizations have a hierarchical structure by the economies of skilled workers. Skilled workers can make decisions without consulting other workers, while unskilled workers need to ask (superior) more skilled workers for advice or approval. Garicano (2000) develops a similar model in which he uses specialization instead of differences in worker skills. He explains the formation of hierarchies by a trade off between communication versus knowledge acquisition costs. In a "knowledge-based hierarchy" easy problems are solved by lower (production) levels, while more exceptional or harder problems need to be passed on to higher levels. In his model the decision "who must learn what and whom each worker should ask when confronted with an unknown problem" is part of the organization.

DeCanio and Watkins (1998) explain organizational structure from information processing by describing an organization as a 'pattern of information exchange among the agents', with an important role for the processing capabilities of the agents. They study the relation between agents' capabilites and network structure. They use simulation to find optimal organization structures depending on the information-processing capabilities of the agents. They conclude that optimal organization structure depends on agents' information processing capabilities, i.e. high information processing capabilities support high degree of connectedness, while low capabilities support more hierarchical structures. The pattern of communication between the agents is described as a network of connected points (a graph) with different graphs corresponding to different organization structures. In our model this network has directed arcs between the agents reflecting the asymmetry between the positions on both sides of the arcs. Although our model does not describe the information processing explicitly, one might think of different flows of information going top-down (for example, assignment of tasks to lower levels) and bottom-up (for example, information about the 
market situation that is known by lower level managers who send this information upwards so that higher management can make policy and corresponding task assignments based on this information), see also Williamson (1967). The information processing capabilities of the agents that plays a central role in DeCanio and Watkins' paper does not play a role in our model. We assume that the positions in our firm model are occupied by agents that have the capacity to do their part of the work. The assumption that our structures are hierarchies then might be supported by acknowledging that not all agents are capable to occupy any firm position (for example lower level workers might not have the knowledge or skills to be higher level managers.) However, DeCanio and Watkins' conclusion that 'flattening of organizations would be one result of improved information processing capability of agents' is in line with our model since high complementarity of labor inputs usually requires more skills than substituable labor.

Finally, the friction between the internal cooperative behavior and the external competitive behavior is solved by accepting some imperfections in the labor markets and some hold up features in human resource management. Baron and Kreps (1999) observe that the Human Resource systems of successful firms, which systems are represented here by the firm's internal governance, often display practices reinforcing consistent themes or messages. Radically different Human Resource systems may exist because they face radically different external forces, but they also can flourish reasonably well in very similar situations, if only they are internally consistent. Consistency is obtained here because the organization's governance is defined in terms of positions or jobs, and is directly adapted to the production technology. Human resource management aims at matching the productivity requirements of the position or the job with the productive capacities of the candidate to be employed.

However, since the reward system is determined by the positional or job-productivity rather than by the individual's productivity outside this context, the productivity of some person depends crucially on the position in the firm's organization. Due to cooperation, the organization will enhance the productivity of that person drastically. Market wages on labor markets therefore refer to the potential match of some individual person with the job-productivity that may result in an organization, and are then assumed to correspond 
with that individual's productivity. In order to emphasize the effect of internal cooperation and positional productivity on individual productivity, it is valid to adopt the extreme case that individual labor is homogeneous. Its productivity is equal to the lowest positional productivity in the firm. Employment in the firm's organization creates firm-specific assets or human capital, which is controlled by the CEO. In the jargon of transaction cost economics, this feature of having all assets controlled by a single entity is called unified governance. Unified governance also increases the agency costs of governance, which will be expressed in our model ${ }^{18}$.

\section{Concluding remarks}

There are several directions in which further research seems promising. In a homogeneous firm as considered in this paper the capacities of workers are identical. In a heterogeneous firm, workers and coordinators are not necessarily identical and their capacities and tasks may vary from very limited, such as routine work on a production line, to very sophisticated, such as work done by a surgeon in a hospital, or by a maitre de cuisine in a restaurant. Heterogeneous outcome functions then allow for heterogeneous organization structures, i.e., organization structures that do not necessarily have constant span of control, and even are not necessarily tree structures. Our approach can also be applied to such a heterogeneous firm.

Secondly, it is relevant to know how strong both in the short run and in the long run the internal cooperative forces are relative to the external competitive forces. The basic idea is that cooperation improves productivity sufficiently such that the firm can afford a labor cost above the reservation wage of labor at the lowest level. Or, said in another way, unschooled and unemployed labor can be made more productive by and employable in a firm with an adequate hierarchical internal organization. Further, labor in society is not homogeneous, but has personal capacities that are traded on differentiated labor markets. This heterogeneous labor interacts with the positions available in the internal organization

\footnotetext{
${ }^{18}$ The unbundling of a firm into two or more firms each having a unified governance, but both governed by the same external organization, can only be analyzed in a more general context, such as the general equilibrium approach developed by Ruys and van de Brink (1999) and Ruys (2002).
} 
of firms. From a dynamic point of view, labor input with a substitutable character that requires a deep internal organization in production, has incentives to transform in character by schooling, differentiation or specialization and to become suited for flat internal organizations.

Third, the permission value as pay system introduced here can be replaced by other systems. We already mentioned in Section 2 that the results obtained there hold for all pay systems satisfying efficiency, vertical monotonicity and symmetry. Other examples of pay systems satisfying these properties are the the egalitarian wage system (which assigns the same wage to each employee position which is equal to the profit assigned to the owner position), and every convex combination of this egalitarian wage system and the permission value $^{19}$.

Fourth, the model developed here fits well in efficiency wage theory as discussed by, e.g., Stiglitz (1976), Akerlof (1984) and Yellen (1984). According to that theory laborers should be paid a rent on their equilibrium wage in order to stimulate them to put full effort in production and prevent them from shirking. A laborer losing its job at equilibrium wages can easily find a new job on the same conditions. However, paying rents on equilibrium wages makes it more difficult for laborers to find a new position on the same conditions, viz., including the same positional rents. Moreover, paying rents on equilibrium wages can induce unemployment which makes it even more difficult to find a job with this positional rent. In our model wages can be higher than the reservation wages of workers. The positional rent of a position, i.e., the difference between the wage of a position and its reservation wage, can be compared to the rent of the efficiency wage.

Finally, the way organizations are treated in the approach presented here may be assessed as rudimentary by bussiness economists and sociologists. However, it offers considerable room to extend its scope. One way is to consider other institutions than markets that can empower and valuate firms or households. Cultural characteristics of societies and non-profit organizations can then be expressed in formal terms and their effects on governance may be estimated. This is discussed for a government system by van den Brink, Ruys and Semenov (1999) and Ruys, van den Brink and Semenov (2000) who use the model developed here to

\footnotetext{
${ }^{19}$ In the context of cooperative TU-games, convex combinations of egalitarian wage systems and Shapley value are considered in Joosten (1996) and Ju, Borm and Ruys (2004).
} 
formalize various cultural dimensions as identified by Hofstede (1980). Other extensions are the introduction of more complicated networks than the ones used here, or the introduction of more dimensions in the governance control parameter. After the seminal work of Coase (1937), the social embeddedness of matches within and between organizations is studied today in a temporal, network and institutional framework, see, e.g., Raub (1977), Gilles, Haller and Ruys (1994), or Weisbuch, Kirman and Herreiner (1998) who study buyer-supplier relations on markets. The basic problem remains the relative importance given to cooperation and to competition and to stimulate, separate and replicate cooperation. That problem will never be exhausted, presumably.

\section{References}

Akerlof, G. (1984), "Gift exchange and efficiency wage theory: four views", American Economic Review Proceedings, 74, 79-83.

Ambec, S. And Y. Sprumont (2002), "Sharing a River", Journal of Economic Theory, 107, 453-462.

Baker, G., R. Gibbons, And K.J. Murphy (2002), "Relational Contracts and the Theory of the Firm", Quarterly Journal of Economics, 117, 39-84.

Baron, J.N., And D.M. Kreps (1999), Strategic Human Resources, John Wiley \& Sons, New York.

Beckmann, M.J. (1988), Tinbergen Lectures on Organization Theory, Springer-Verlag, Berlin.

Beggs, A.W. (2001), "Queues and Hierarchies", Review of Economic Studies, 68, 297-322.

BRINK, R. VAN DEN (1996), "Skewness of the income distribution in a firm and the substitutability of labor inputs", Research Memorandum FEW 739, Tilburg University.

BRINK, R. VAN DEN (1997), "An axiomatization of the disjunctive permission value for games with a permission structure", International Journal of Game Theory, 26, 27-43.

BRink, R. VAN DEN, AND R.P. GILles (1996), "Axiomatizations of the conjunctive permission value for games with permission structures", Games and Economic Behavior, $12,113-126$.

BRINK, R. VAN DEN, AND R.P. Gilles (2003), "Explicit and Latent Authority in Hierarchical Organizations ", Tinbergen Discussion paper 03-102/1, Free University Amsterdam. 
Brink, R. van Den, P. Ruys, And R. Semenov (1999) Governance of clubs and firms with cultural dimensions, CentER Discussion Paper 99101, Tilburg University.

CoAse, R.H (1937), "The Nature of the Firm," Economica 4, 386-405.

Coleman, J.S. (1980), "Authority systems", Public Opinion Quarterly, 44, 143-163.

Curiel, I. (1988), Cooperative Game Theory and Applications, Ph.D Thesis, Katholieke Universiteit Nijmegen.

DeCanio, S.J., And W.E. Watkins (1998), "Information Processing and Organizational Structure", Journal of Economic Behavior and Organization, 36, 275-294.

Everett, M.G., And S.P. Borgatti (1991), "Role coloring a graph", Mathematical Social Sciences, 26, 183-188.

Furubotn, E.G. (2001), "The New Institutional Economics and the Theory of the Firm", Journal of Economic Behavior and Organization, 45, 133-153.

Garicano, L. (2000), "Hierarchies and the Organization of Knowledge in Production", Journal of Political Economy 108, 874-904.

Gilles, R.P., G. Owen, And R. van DEn Brink (1992), "Games with permission structures: the conjunctive approach", International Journal of Game Theory, 20, 277-293.

Gordon, D.M. (1994), "Bosses of different stripes: a cross-national perspective on monitoring and supervision", The American Economic Review, AEA Papers and Proceedings, 375-379.

Graham, D.A., R.C. Marshall, and J.F. Richard (1990), "Differential Payments Within a Bidder Coalition and the Shapley Value", American Economic Review 80, 493-510.

Grossman, S.J., And O.D. Hart (1983), "An Analysis of the Principal-Agent Problem," Econometrica 51, 7-45.

Grossman, S.J., and O.D. Hart (1986), "The costs and benefits of ownership: a theory of vertical and lateral integration," Journal of Political Economy 94, 691-719.

Hamers, H. (1995), Sequencing and Delivery Situations: a Game Theoretic Approach, Ph.D Thesis, University of Tilburg.

HARSANYI, J.C. (1959), "A bargaining model for cooperative n-person games," in Contributions to the Theory of Games IV (A.W. Tucker and R.D. Luce, Eds.), pp. 325-355. Princeton UP, Princeton.

Hart, O., AND J. Moore (1990), "Property rights and the nature of the firm," Journal of Political Economy 98, 1119-1158.

Hart, O., AND J. Moore (1999), "Foundations of incomplete contracts," Review of Economic Studies 66, 115-138.

Holmström, B. (1979), "Moral Hazard and Observability", Bell Journal of Economics, 10, 74-91. 
Hofstede, G. (1980), Culture's Consequences. International Differences in Work-Related Values, Sage Publications.

Joosten, R. (1996), Dynamics, Equilibria and Values, Dissertation, Maastricht University.

Ju, Y., P.E.M. Borm, And P.H.M. Ruys (2004), "The consensus value : a new solution concept for cooperative games", Center Discussion paper 2004-50, Tilburg University, The Netherlands.

Keren, M., AND D. Levhari (1979), "The optimum span of control in a pure hierarchy", Management Science, 25, 1162-1172.

Keren, M., And D. LeVhari (1983), "The internal organization of the firm and the shape of average costs", Bell Journal of Economics, 14, 474-486.

Kessler, A.S. (2000), "On Monitoring and Collusion in Hierarchies", Journal of Economic Theory, 91, 280-291.

Maniquet, F. (2003), "A Characterization of the Shapley Value in Queueing Problems", Journal of Economic Theory, 109, 90-103.

MASkin, E., Y. QIAN, AND C. Xu (2000), "Incentives, Information and Organizational Form", Review of Economic Studies, 67, 359-378.

Maskin, E., And J. Tirole (1999), "Unforeseen contingencies and incomplete contracts," Review of Economic Studies, 66, 83-114.

Milgrom P., AND J.RoberTs (1994), "The economics of modern manufacturing: technology, strategy and organization", American Economic Review, 80, 511-528.

Pekec, A., And F.S. Roberts (2001), "The role assignment model nearly fits most social networks", Mathematical Social Sciences, 41, 275-293.

Prescott, E.S., And R.M. Townsend (2002), "Collective Organizations versus Relative Performance Contracts: Inequality, Risk Sharing and Moral Hazard", Journal of Economic Theory, 103, 282-310.

QIAN, Y. (1994), "Incentives and loss of control in an optimal hierarchy", The Review of Economic Studies, 61, 527-544.

RADNER, R. (1992), "Hierarchy: the economics of managing", Journal of Economic Literature, 30, 1382-1415.

Rajan, R.G., And L. Zingales (1998), "Power in a Theory of the Firm", Quarterly Journal of Economics, 113, 387-432.

Rajan, R.G., And L. Zingales (2001), "The Firm as a Dedicated Hierarchy: A Theory of the Origins and Growth of Firms", Quarterly Journal of Economics, 116, 805-851.

Rosen, S. (1982, "Authority, control, and the distribution of earnings", Bell Journal of Economics, 13, 311-323. 
Rothschild, R. (2001), "On the Use of a Modified Shapley Value to Determine the Optimal Size of a Cartel", Journal of Economic Behavior and Organization, 45, 37-47.

Ruys, P.H.M., AND R. VAN DEN BRINK (1999), "Positional abilities and rents on equilibrium wages and profits", in: The Theory of Markets, eds. J.J Herings, G. van der Laan, and A.J.J Talman, North-Holland, pp. 261-279.

Ruys, P.H.M., R. van den Brink and R. Semenov (2000), "Values and governance systems", in: Institutions, Contracts, Organizations: Perspectives from New Institutional Economics, ed. C. Ménard, Edward Elgar Publishing Co., pp 422-445.

Shapley, L.S. (1953), "A value for $n$-person games", in Annals of Mathematics Studies 28 (Contributions to the Theory of Games Vol.2) (H.W. Kuhn and A.W. Tucker, Eds.), pp. 307-317. Princeton: Princeton UP.

Shapley, L.S. (1971), "Cores of convex games", International Journal of Game Theory, 1, $11-26$.

Simon, H. (1991), "Organizations and markets", Journal of Economic Perspectives, 5, 2544.

Stiglitz, J. (1976), "The efficiency wage hypothesis, surplus labour, and the distribution of income in L.D.C.'s", Oxford Economic Papers, 28, 185-207.

Teece, D.J. (1996), "Firm Organization, Industrial Structure and Technological Innovation", Journal of Economic Behavior and Organization, 31, 193-224.

Williamson, O.E. (1967), "Hierarchical control and optimum firm size", Journal of Political Economy, 75, 123-138.

YelLen, J.L. (1984), "Efficiency wage models of unemployment", American Economic Review Proceedings, 74, 200-205. 